\title{
Elecciones municipales en el Estado de México: un análisis del contexto local
}

Jaime Sobrino

El Colegio Mexiquense

Resumen

El objetivo del presente artículo consiste en exponer las principales características de los tres últimos procesos electorales en el Estado de México para elegir Ayuntamientos. Para ello, se parte de un análisis sobre el significado y las funciones de los gobiernos locales, su relación con los procesos electorales, y una revisión al concepto y desarrollo de la disciplina de geografía electoral.

\section{Gobiernos locales y procesos electorales}

El gobierno local es una forma de autogobierno que se encarga de la administración de los aspectos públicos en cada localidad y se compone de un cuerpo de representantes de la comunidad. Está sujeto al gobierno central de muchas maneras, pero posee una considerable cantidad de responsabilidad y poder discrecional. El gobierno local es una forma de descentralización de funciones públicas delimitadas a un contexto territorial (Byrne, 1986:1).

Entre los rasgos estructurales significativos del gobierno local destacan: el ser un poder comunitario, porque está basado y sostenido por la realidad social más inmediata y concreta; ser un poder localizado, por estar sometido a la geografía y realidad natural; y ser un poder con responsabilidad, ya que aunque depende del gobierno 
central en cuanto a su autonomía o subordinación, posee personalidad jurídica y moral (Massé, 1993:45-46).

Los gobiernos locales contienen un número de características distintivas que les permiten identificarse como una forma particular de administración pública. Entre dichas características aparecen, según Byrne (1986:2-3): a) ser electo por medio de un proceso electora formal; b) desempeñar un gran número de funciones; $c$ ) tener una escala local de operación; $d$ ) tener una estructura orgánica claramente definida; $e$ ) estar subordinado al gobierno central mediante un marco jurídico y legal; y $f$ ) tener un sistema tributario propio.

El artículo 115 de la Constitución del país menciona que el municipio es la base de la división territorial y organización política y administrativa de los estados. El municipio es administrado por un Ayuntamiento de elección popular directa; está investido de personalidad jurídica y maneja su patrimonio conforme a la ley; tiene a su cargo una serie de servicios públicos, y facultades para formular, aprobar y administrar la zonificación y los planes de desarrollo urbano municipal.

Los gobiernos locales desempeñan una serie de funciones o actividades, las cuales han sido divididas de diversas maneras. Así, se tiene una primera visión, derivada de la teoría económica urbana, en la cual se vislumbran cuatro tipos de funciones: prestación de servicios públicos, inversión, financiamiento y regulación (Hirsh, 1977:430 438).

La prestación de servicios públicos constituye la función principal y prístina del municipio. Se refiere a la cantidad y calidad de servicios proporcionados, así como a los agentes y modalidades que intervienen en el suministro. Esta función se delimita jurídicamente, y para el caso mexicano, el artículo 115 constitucional establece que los municipios tendrán a su cargo los servicios públicos de agua potable y alcantarillado, alumbrado público, limpia, mercados y centrales de abasto, panteones, rastros, calles, parques y jardines, seguridad pública y tránsito, y los demás que las legislaturas locales determinen.

A lo largo del presente siglo, los gobiernos locales han incrementado la cantidad y variedad de servicios públicos suministrados. Esto a consecuencia del avance en los niveles de bienestar de la población, el desarrollo en la aceptación y formalización de necesidades sociales, y la transferencia o descentralización funcional desde el poder central al local. Los servicios públicos se pueden dividir en cuatro tipos (Richards, 1983:5972):

\begin{abstract}
Servicios de protección, que constituyen una de las divisiones más función es negativa en carácter ya que consisten en la promoción de bienes para reducir riesgos. En este rubro se incluyen las centrales de bomberos, estaciones de policía, manejo de residuos sólidos, inspección sanitaria y de pesos y medidas.
\end{abstract}

Servicios comunales, los cuales proporcionan beneficios para toda la población en un sentido más positivo que los anteriores. Se conforman por planeación territorial, vialidades, alumbrado, parques y jardines.

Servicios personales, para asistencia directa a aquellas personas que lo necesitan. Son las actividades más costosas para el gobierno local, pero muchas de ellas se proporcionan sin costo subsidiadas por lo que contribuyen a redistribución del ingreso y reducción de desigualdades sociales. La educación, salud y asistencia local son ejemplos de estos servicios.

Servicios comerciales, ofrecidos por el gobierno en competencia o de manera complementaria a la iniciativa privada.

Las funciones de inversión corresponden a la serie de mecanismos y estrategias financieras que desarrollan los gobiernos locales para la construcción y operación de los soportes materiales de los servicios públicos. Dada la escasez de recursos financieros, los gobiernos se enfrentan a la toma de decisiones entre proyectos alternativos, procurando elevar el nivel de satisfacción, pero también para responder a las expectativas de la población derivadas del proceso político electoral.

Para cumplir con las dos funciones anteriores, los gobiernos locales cuentan con opciones de financiamiento, por lo que las finanzas públicas locales son elemento clave para el gobierno y la administración, pues gracias a ellas se realizan las distintas acciones y actividades que le han sido atribuidas. El financiamiento procede de recursos propios, así como de créditos y transferencias realizadas por el gobierno central.

Finalmente, las funciones de regulación se vinculan con las distintas reglamentaciones elaboradas para el ordenamiento del territorio y la actuación de los distintos agentes sociales. Estas tareas de regulación serían, en un sentido más modesto, el equivalente de las tareas legislativas del gobierno central.

Otro punto de vista en la clasificación de funciones de los gobiernos locales, es aquella establecida a partir de la distribución del gasto público. Según ésta, los gobiernos asumen tres funciones 
generales: estabilización, redistribución y asignación de recursos (Muth, 1975:361-363).

Las funciones de estabilización se refieren a aquellas vinculadas con el comportamiento de las variables macroeconómicas. Son generalmente competencia de los gobiernos centrales y en ellas las administraciones locales inciden muy poco. Sin embargo, las consecuencias del desarrollo económico global tienen necesariamente un repercusión espacial, por lo que los gobiernos locales son los encargados de resolver los problemas y conflictos que se generan en su territorio y sociedad.

Por otro lado, las funciones de redistribución tienen la finalidad de mejorar el bienestar de la población o corregir la distribución de recursos derivada del mercado. Dichas funciones se llevan a cabo a partir de la prestación de servicios públicos como educación, salud, vivienda y asistencia social. La provisión de estos servicios tiende a mejorar las desigualdades espaciales y sociales, y se les denominan bienes sociales.

Las funciones de asignación de recursos se relacionan con la producción y dotación de ciertos bienes y servicios en los cuales el consumo de una persona no afecta el de los demás, por lo que se denominan bienes públicos puros que no son divisibles y no son ofertados por el mercado. Estos bienes pueden ser locales, metropolitanos o regionales. Los locales incluyen servicios como bomberos, policía, bibliotecas, parques y jardines; los de ámbito metropolitano o regional son vialidades, autopistas, agua potable, electricidad, terminales, y planeación territorial.

Existe otro tipo de clasificación de funciones derivada de la ciencia política. Desde este punto de vista, los gobiernos locales asumen dos tipos de funciones: sustantivas y adjetivas (Martínez, 1993:120-142).

Las funciones sustantivas o fundamentales se relacionan con el concepto de gestión municipal, es decir, el conjunto de acciones que tienen la finalidad de salvaguardar los intereses comunes de la localidad. Estas funciones incluyen: prestación de servicios públicos, desarrollo económico y social, desarrollo urbano, y acciones de trabajo comunitario y participación ciudadana. Por lo que atañe a las funciones adjetivas o complementarias, se conciben como acciones desempeñadas porla administración municipal paradar cumplimiento a los fines del gobierno local. Éstas involucran a la planeación, hacienda local, administración del personal y recursos materiales.

Una cuarta clasificación de funciones se puede obtener a partir de los conceptos de la administración pública. Desde esta perspectiva, los gobiernos locales cumplen dos grandes funciones: administración del territorio y gobierno político (Ziccardi, 1994:89-103).

Las funciones de administración del territorio incluyen todas aquellas acciones que el gobierno central ha transferido a los locales, con la finalidad de avanzar en la descentralización funcional. En ellas se pueden englobar la prestación de servicios públicos, el manejo de la hacienda local, y la elaboración de planes de desarrollo territorial.

Para el cumplimiento de estas funciones, el presidente municipal forma un equipo de trabajo denominado "administración municipal". En México no existen reglas claras para el reclutamiento de personal, por lo que es urgente que exista una carrera de funcionario municipal que garantice la capacitación de quienes manejan la administración local. Estas tareas de capacitación se han encomendado de facto a los institutos estatales de administración pública.

Las administraciones locales entablan un conjunto de relaciones intergubernamentales con el gobierno estatal y con diferentes instituciones del federal. Dichas relaciones permiten en gran medida cumplir con éxito las promesas de gobierno, así como asegurar las acciones de inversión y prestación de servicios públicos.

Recientemente se ha realizado una serie de estudios tendentes al análisis de los cambios o innovaciones que han ido adoptando algunas administraciones municipales en el país. La innovación municipal es un proceso detonador de reconfiguración institucional en el ámbito de una administración municipal, capaz de generar un conjunto de resultados que mejoren las estructuras de gobernabilidad y calidad de la gestión municipal (Cabrero, García y Gutiérrez, 1995:30). Si bien estas innovaciones parten de la recomposición en las funciones administrativas del municipio, tienen injerencia también en las funciones de gobierno, ya que estas últimas son las encargadas de promover, fomentar, consolidar y mantener dichas innovaciones.

Las innovaciones municipales pueden ser de tres tipos(Conde, 1996:4): a) técnicas, cuando se usan nuevas formas, tecnologías o modos de financiamiento para la prestación de servicios públicos, o cuando se ponen a disposición de los habitantes nuevos productos y servicios; b) administrativas, asociadas con procesos de simplificación administrativa, nuevos mecanismos de atención a la ciudadanía y cambios en la estructura organizativa; y c) de interrelación entre agentes, entendidas como aquellas encaminadas a la apertura de la participación ciudadana para promover prácticas democráticas de gestión administrativa y de gobierno. 
Para el cumplimiento de las funciones de gobierno político, la ciudadanía elige por medio del voto directo y en planilla única a los representantes de los partidos políticos que ocuparán la presidencia municipal y los cargos del Ayuntamiento o cabildo (síndicos, regidores de mayoría relativa y regidores de representación proporcional). Las elecciones municipales representan el proceso mediante el cual se designa al Ayuntamiento o cuerpo político representativo del gobierno local. Las elecciones locales acercan a los ciudadanos al proceso de decisión; éstas se desarrollan en un marco restringido y concierne a candidatos mucho más próximos a sus electores con relación a las elecciones estatales o federales.

El sistema electoral es un elemento del sistema político que permite a la ciudadanía participar en las decisiones políticas que proponen los partidos. La participación ciudadana en los procesos electorales tiene la finalidad de aceptar o rechazar la plataforma política de los partidos contendientes. Con la elección se asegura la representación de los gobernados, a la vez que se da pauta para el surgimiento y desarrollo de partidos políticos, los cuales se convierten en intermediarios entre electores y gobernantes (Cotteret y Emeri, 1973:113).

El sistema electoral influye en la estructura y dinámica del sistema de partidos políticos en el poder. La estructura presenta cuatro tipos principales: a) partido monopolista, cuando un solo partido concentra más de $80 \%$ de los puestos de elección; $b$ ) partido dominante, cuando un partido obtiene entre 60 y $80 \%$ de los puestos de elección; c) bipartidismo, cuando un partido gana en no más de $60 \%$ de los casos y otro en no menos de $30 \%$; y d) multipartidista, cuando un tercer partido alcanza 10\% o más de los puestos de elección. Para conocer la estructura de un sistema regional, los puestos de elección conseguidos por cada partido político pueden ser remplazados por el porcentaje de población que en dicha región es gobernada por cada partido político.

En el caso de una estructura de partido único o monopolista se genera una dictadura de partido. El sistema electoral participa en la unión del partido con el Estado, por lo que se obtiene una ideología de "Estado partidista". Por otro lado, una estructura multipartidista es un elemento a priori de inestabilidad en la gobernabilidad, dado que las alianzas entre partidos deterioran su identidad organizativa. Cuando las alianzas se llegan a establecer, las más estables ocurren entre partidos opositores (ideológicamente lejanos), mientras que las de partidos competidores (próximos ideológicamente) son más complicadas y vulnerables por la semejanza de principios y ambiciones políticas (Panebianco, 1982:411-416).

La dinámica del sistema de partidos políticos se expresa mediante los cambios -o permanencia - en las preferencias de los electores y la.geografía electoral del territorio de referencia. Con el paso del tiempo se conforma un sistema con un partido en el poder, partidos de oposición y gobiernos de coalición. Existen cinco factores que influyen en el comportamiento de la dinámica del sistema:

1. Existencia de partidos políticos. A mayor cantidad, mayores cambios en la estructura del sistema de partidos políticos.

2. Frecuencia de la elecciones. A mayor frecuencia, menores cambios.

3. Tamaño de población. Cuanto más grande es una población -local o nacional- menores serán los cambios esperados.

4. Migración. Los territorios que presentan mayores tasas de inmigración tendrán menores cambios.

5. Calidad de vida. A mayor calidad de vida, derivada de la provisión de servicios públicos, menores cambios.

El proceso electoral es la serie de actividades, tareas y decisiones que realizan los organismos electorales, partidos políticos y ciudadanos, encaminados a elegir a los integrantes del gobierno (López, 1988:52). Este proceso se conforma por tres fases: a) preparación de los comicios (registro de electores, designación de organismos político-electorales, registro de candidatos, preparación de documentos e integración de la mesa de casilla); b) jornada electoral (recepción física de sufragios y escrutinio); y c) actos posteriores (cómputo de votos, levantamiento de actas, registro y entrega de constancias de mayoría, calificación de las elecciones y toma de posesión).

Este proceso está regido por una legislación electoral que marca los procedimientos para la elección del poder ejecutivo y legislativo, según lo indicado en los preceptos constitucionales. En el caso de México, las elecciones federales se ciñen a lo establecido en el Código Federal de Instituciones y Procedimientos Electorales 
(COFIPE), mientras que las estatales y municipales, a las legislaciones elaboradas por cada estado. Estas legislaciones generalmente siguen de cerca y adecúan sus propias características a la ley federal electoral en vigor, pero no es obligación ni regla, ya que varias entidades tardan tiempo para adoptar y adaptar las normas federales, e incluso se presentan casos en que algunas disposiciones son distintas o contrarias a las vigentes en el ámbito federal (Crespo, 1996:9).

La participación ciudadana en el proceso electoral es un indicador de la cultura política, que se define como el conjunto de actividades, sentimientos y valores que actúan sobre la conducta política de un individuo (Pacheco, 1991:37). Existe un precepto generalizado de que la cultura política alcanzada por la población está determinada por el grado de información recibida; sin embargo, existe un campo de formación de opinión que pasa por mecanismos subjetivos que no están necesariamente sujetos a la lógica de la racionalidad. Un elector puede ser comparado con un consumidor racional en el que opera un cálculo de costo-beneficio y satisfacción de necesidades para decidir el consumo dentro de un espectro de bienes y servicios existente. Mientras que el individuo como consumidor decide su consumo en función del ingreso y sus necesidades, como elector lo hace a partir de su cultura política, en la que intervienen no sólo aspectos racionales (como podrían ser el ingreso y las necesidades para el consumidor), sino además elementos subjetivos y coyunturas que se presentan en el momento de la votación.

Pero además, puede ocurrir que el individuo simplemente se abstenga de acudir a las urnas y sienta que asume una actitud racional. El abstencionista no acude a las urnas porque siente que su voto no vale (posición racional), porque no está informado (cultura política objetiva), o porque la vida pública no le interesa (cultura política subjetiva). El abstencionista no informado es "apático" de los procesos electorales y tiene mayor presencia entre los sectores populares, especialmente mujeres; mientras que el que no ve opciones es un abstencionista "activo" y tiene mayor presencia en las clases medias y altas de la sociedad (Salazar y Emmerich, 1993:168-171).

Una de las características del proceso electoral es que el voto es secreto, por lo que no se puede saber con exactitud quiénes votaron y por qué lo hicieron así. Existen dos enfoques que han dominado el campo de estudio a estas dos preguntas: la psicología electoral y la sociología electoral. El primer enfoque analiza la racionalidad, la irracionalidad, el super-ego político del elector, así como los comportamientos electorales de identificación y rechazo. El segundo atañe al estudio del comportamiento electoral de grupos sociales (Sanguín, 1981:109-113).

Los factores que explican la pregunta quiénes votaron son los siguientes (Byrne, 1986:96-97):

1. Edad. La población menor a 35 años parece votar menos que la de mayor edad.

2. Género. Parece no haber gran diferencia, aunque las mujeres jóvenes casadas son menos propensas al voto.

3. Clase social. En países como Inglaterra se ha observado poca diferencia en los niveles de participación por grupos sociales, mientras que en otros, como los Estados Unidos, existe una mayor presencia de la clase media.

4. Activistas. Los miembros o simpatizantes de algún partido político muestran mayor participación frente al resto de la población.

5. Posesión de casa-habitación. Los propietarios son más propensos al voto en comparación con los arrendadores.

6. Inmigrantes. Presentan menor propensión al voto, sobre todo en elecciones locales.

Para avanzar en la respuesta al por quéla sociedad votó de esa manera, se ha desarrollado todo un cuerpo teórico y metodológico denominado geografía electoral, la cual privilegia la relación entre el comportamiento de los electores y la estructura espacial, a partir del análisis de la distribución geográfica del voto, de las relaciones causales entre resultados electorales y características socioeconómicas y demográficas de la población, así como de las consecuencias de la fragmentación del electorado en distintas delimitaciones territoriales (Graizbord y Sobrino, 1990:228). A continuación se abordará este campo de estudio. 


\section{Sobre la geografía electoral}

La geografía electoral es una rama de la ciencia política que estudia la distribución territorial de los votos, bajo el supuesto de que dicha distribución esconde y revela pautas sociodemográficas de distribución de las preferencias electorales (Emmerich, 1993:11). Para ello, se utiliza el método ecológico, que consiste en relacionar los resultados electorales (variable dependiente) con los perfiles sociodemográficos de las zonas respectivas (variables independientes). Esta disciplina tiene una larga historia intelectual. El mapeo de los resultados electorales han ilustrado señales importantes en la operación de los gobiernos modernos, pero también ha sido víctima de un gran empirismo.

Durante la década de los cincuenta, la ciencia política fue dominada por un tipo de análisis empírico del comportamiento electoral. Este análisis establecía las actitudes reportadas y las características de los votantes individuales por medio de muestreos que permitían obtener inferencias de la población total (Johnston, Shelley y Taylor, 1990:2). El método de comportamiento estaba ligado a un concepto de gobierno democrático, liberal y multipartidista, en el cual los gobiernos eran elegidos a partir de una competencia abierta entre partidos políticos, los cuales ofrecían plataformas optativas para un interés racional de los electores. E votante actuaba de manera racional, ya que buscaba incrementar su utilidad individual (Downs, 1957:17-36).

El predominio del análisis del comportamiento electoral en la ciencia política relegó a un segundo plano a la geografía electoral en los años cincuenta y mediados de los sesenta. El punto era explorar la utilidad racional del elector, sin importar su localización espacial. Sin embargo, este análisis empezó a ceder frente a la geografía electoral hacia finales de los sesenta, como resultado de la impugnación a sus dos premisas fundamentales: la veracidad del pluralismo liberal, y las dudas sobre la actitud racional y objetiva de los electores.

A partir de los sesenta, la geografía electoral ha desarrollado diversos métodos de estudio, a partir del reconocimiento de que la selección de gobiernos se basa en decisiones de votantes individuales y la suma de sus preferencias. Cabe mencionar que a partir de esa fecha, la geografía electoral se ha ligado en mayor o menor grado con el campo de estudio de la teoría social, no obstante que aún en la actualidad se considera como parte de la ciencia política.
Los estudios de geografía electoral con una perspectiva de teoría social han tenido cuatro enfoques fundamentales (Johnston, Shelley y Taylor, 1990:15-21):

1. Geografía del comportamiento electoral, impulsado por la escuela francesa de sociología electoral, e inspirado en los análisis de comportamiento elaborados en la década de los cincuenta.

2. Efecto geográfico de los flujos de información en el comportamiento electoral individual, relaciones interpersonales y conformación de una cultura política de la sociedad. Bajo esta perspectiva, el comportamiento del electorado está en función del cúmulo de información política recibida.

3. Geografía del sistema electoral, privilegiando el estudio de los mecanismos y variables asumidos para la fragmentación del territorio en distritos electorales, y los efectos de dicha división espacial en los resultados de la votación.

4. Relaciones entre la geografía del desempeño electoral y el sistema de partidos políticos existente; los trabajos se centran en verificar relaciones entre la organización, plataforma y movilización de los partidos políticos, y su efecto en las decisiones del electorado.

Cada enfoque puede ser tratado a partir de una escala de análisis y de las causas del comportamiento electoral. Las escalas de análisis más empleadas han sido individuos, grupos pequeños, grupos sociales amplios, división del territorio en centro y periferia y contextos locales; por otro lado, dentro de las causas del comportamiento se han privilegiado: la información, la economía pública y su relación con la calidad de vida de la población, los conflictos entre clases sociales derivadas del sistema capitalista, y las costumbres y los patrones de vida cotidiana.

La principal demanda hacia el cambio de la geografía electoral con un paradigma de teoría social, radica en que las categorías nacionales no son empíricamente apropiadas o teóricamente coherentes para explicar las causas del comportamiento electoral. La 
causalidad de este comportamiento puede ser descubierta sólo a partir del estudio de mecanismos sociales específicos que trasladen una estructura social en actos individuales. Desde este punto de vista, la geografía electoral ha cambiado su foco de atención desde la psicología del votante individual -y racional- hacia la historia de los lugares y partidos políticos.

Una de las ramas con mayor desarrollo en la geografía electoral es la del contexto local, que examina a la geografía electoral en términos de la experiencia cotidiana dentro de grupos sociales asociados a lugares particulares. En esta microsociología espacial se analizan contextos específicos que tienen características propias como son: historia, desarrollo socioeconómico, interrelaciones externas y tradiciones particulares. Los lugares constituyen el contexto social en el que se expresan las preferencias políticas.

Los estudios sobre temas electorales en el país tienen una larga tradición que data de la década de los treinta, pero a partir de los ochenta se evidenció un aumento notable en el número de libros, artículos y ensayos realizados. Una recopilación bibliográfica de 1988 (Arreola y Molinar, 1988) mostraba 465 títulos de libros, artículos, capítulos, ensayos periodísticos, ponencias y declaraciones, enfocadas básicamente al tratamiento de la democracia, reforma política, partidos políticos, resultados electorales, y legislación electoral. Del total de títulos, 110 correspondían a bibliografía regional sobre temas en poderes locales, municipios y descentralización, elecciones locales y participación ciudadana. Por otro lado, un libro que presenta la evolución de la investigación urbana y regional en México de 1940 a 1991 , seleccionó 1,831 libros y artículos que incorporaban como nivel de análisis la dimensión urbana o regional (Garza, 1996). De ellos, poco más de cuarenta títulos se referían a estudios sobre comportamiento político, movimientos sociales, grupos de poder locales y participación ciudadana.

En la producción literaria sobre elecciones en México, los estudios acerca de la geografía electoral son relativamente recientes dado que los comicios tenían resultados fácilmente previsibles: el triunfo casi invariable del PRI, lo que propiciaba una estructura en el sistema de partidos de tipo monopolista y una pobre dinámica en el mismo. A pesar de lo anterior, los trabajos pioneros mostraron ciertas características en los resultados electorales del país. Autores como Rafael Segovia, Pablo González Casanova, Carlos Martínez Assad y Juan Molinar Horcasitas, encontraron en sus estudios durante los años setenta y ochenta, que los porcentajes de votación por el PRI eran directamente proporcionales a las características rurales de los territorios, por lo que una de las evidencias iniciales en el comportamiento electoral del país era la dualidad rüral-urbana, priísta la primera, más opositora la segunda (Emmerich, 1993:9-13).

$\mathrm{El}$ avance de la oposición y sus triunfos en algunas elecciones municipales, pero sobre todo los resultados de las elecciones para presidente, diputados y senadores de 1988, propiciaron una mayor atención hacia lo ocurrido y dieron un impulso definitivo a la realización de estudios, ensayos y reflexiones sobre el tema, incluyendo la geografía electoral.

Dicho avance de la oposición se puede ilustrar con lo siguiente: en 1989, los electores de Baja California votaron por el primer gobernador no priísta del México contemporáneo; en 1992, de los 2,389 municipios, el PRI gobernaba en 2,131, contra 99 del PRD, 79 del PAN, 20 del PARM, y 60 de otros partidos y concejos municipales (SEGOB, 1992); en 1994, el PAN gobernaba en 103 Ayuntamientos, contra 85 del PRD, 50 de otros partidos y 2,154 del PRI (SEGOB, 1994:64); finalmente, en 1996, y según datos de la dirigencia nacional del PAN, el PRI tenía en su poder los Ayuntamientos de 1,943 municipios, frente a 248 del PAN diseminados en 26 entidades federativas, 222 del PRD en 21 estados, y 17 de otros partidos políticos. Cabe mencionar que al finalizar 1996, en los 470 municipios gobernados por el PAN y el PRD vivían poco más de 43 millones de mexicanos, equivalentes a $47.4 \%$ de la población nacional ( $E l$ Universal, 23-XII-1996 y El Financiero, 5-1-1997).

Por lo general, los estudios de geografía electoral realizados en el país parten del enfoque del comportamiento de los electores, en el que se presentan resultados oficiales de las elecciones (federales, estatales o municipales), y la relación (o asociación estadística) entre el voto y los atributos de la población. Siguiendo con este enfoque, a continuación se presentan los resultados de los tres últimos procesos electorales del Estado de México para elegir a sus gobiernos locales.

\section{Elecciones municipales en el Estado de México}

Como ya se mencionó, una de las características del gobierno local es que resulta electo por la ciudadanía en un proceso electoral democrático (en teoría) que se caracteriza por el derecho al voto secreto, la organización y administración de las elecciones bajo la responsabilidad de ciertos órganos imparciales, ladifusióninformativa de las elecciones, y el resultado de la elección de manera directa e inmediata. 
Los electores pueden tener la impresión de que su voto es muy importante para el futuro desarrollo del municipio. Sin embargo, los niveles de participación son menores con relación a los procesos federales o estatales, debido a la debilidad real del Ayuntamiento para desempeñar sus distintas funciones. Las elecciones municipales en el Estado de México son ejemplo de lo anterior: entre 1981 y 1996 el promedio de abstencionismo en las elecciones de presidentes municipales llegó a $51.1 \%$, contra $44.7 \%$ para diputados federales, $39.7 \%$ para gobernador, y $35.4 \%$ para presidente de la República. Esto significa que la población mexiquense le ha dado mayor importancia a los comicios para elegir jefe del Ejecutivo nacional y estatal, apartándose de las urnas a la hora de renovar alcaldías.

El Estado de México se compone de 122 municipios, de los cuales Valle de Chalco Solidaridad es el más reciente al erigirse en noviembre de 1994. La superficie total del estado es de $22,183.7 \mathrm{~km}^{2}$, equivalentes a $1.13 \%$ de la nacional. Los municipios presentan gran heterogeneidad en tamaño, siendo los mayores: Tejupilco $(1,327.6$ $\mathrm{km}^{2}$ ), San Felipe del Progreso (856.1), y Tlatlaya (798.9); por otro lado, los de menor tamaño son Polotitlán $\left(3.6 \mathrm{~km}^{2}\right)$, Almoloya del Río (6.4), y Chiconcuac (6.9).

Según datos definitivos del conteo de población de 1995 (INEGI, 1996a), el Estado de México tenía 11,707,964 habitantes, participando con $12.84 \%$ de la población total del país. Durante el quinquenio 1990-1995, el estado registró una tasa de crecimiento total de $3.17 \%$ anual promedio, superior a la experimentada en la década de los ochenta, de $2.70 \%$; por lo que su dinámica demográfica observó un repunte, en contraste con el descenso manifestado a nivel nacional. Del crecimiento total en el primer quinquenio de los noventa, $2.26 \%$ fue producto del crecimiento natural, y $0.91 \%$, del social. En esos cinco años, la entidad consiguió una categoría de atracción moderada de población, con un saldo neto migratorio de 546,113 habitantes.

Con los resultados definitivos del conteo de población 1995 y la tasa de crecimiento total 1990-1995 de cada municipio, la población estimada al 1 de enero de 1997 era de 12,168,654 habitantes. Ésta presentaba una distribución espacial caracterizada por la gran concentración en pocos municipios y dispersión en la gran mayoría de éstos. Los más importantes, desde el punto de vista demográfico, eran Ecatepec, Nezahualcóyotl, Naucalpan, Tlalnepantla y Toluca. En ellos habitaba $40.2 \%$ de los mexiquenses; mientras que los 50 municipios con menor población albergaban únicamente a $5.4 \%$ (véase el cuadro anexo).
El Estado de México es la segunda entidad del país desde el punto de vista de su aportación al producto interno bruto (PIB) nacional. En 1993 generó 118.6 mil millones de pesos (a precios de 1993), participando con $10.5 \%$ del PIB total del país. Su estructura económica se especializaba en las grandes divisiones de industria manufacturera, que aportaba $17.4 \%$ del PIB nacional, y el sector de la construcción, con 10.9\% (INEGI, 1996b:3-42).

La distribución territorial del PIB estatal acusaba mayores niveles de concentración-dispersión respecto ala variable demográfica. Los cinco municipios más importantes (Naucalpan, Tlalnepantla, Toluca, Ecatepec y Cuautitlán Izcalli) generaban $67.6 \%$ del PIB del estado, en tanto que los 50 con menor generación de valor agregado apenas contribuían con 1.7 por ciento.

La heterogénea distribución de población y actividades económicas sobre el suelo mexiquense, propicia la existencia de regiones. El Plan de Desarrollo del Estado de México 1993-1999, identifica ocho regiones y 26 subregiones que en general cumplen requisitos de homogeneidad; están integradas por municipios completos y serían base para identificar proyectos de desarrollo específicos (Gobierno del Estado de México, 1993a:IV-82 a IV-87) Para fines de análisis de los procesos electorales en el ámbito municipal, se empleará la siguiente regionalización (para los criterios de regionalización, véase Sobrino y Garrocho, 1995:54-78) (mapa 1):

I. Región metropolitana de la ciudad de México.Integrada por 28 municipios y una población estimada en 8,526,906 habitantes, al 1 de enero de 1997.

II. Región metropolitana no conurbada.- Compuesta por 27 municipios y 555,074 habitantes.

III. Región del valle de Toluca.- Formada por 25 municipios y 1,590,279 habitantes.

IV. Región norte.- Concentra 16 municipios con una población de 792,621 habitantes.

v. Región sur.- Conformada por 26 municipios y 703,774 habitantes. 

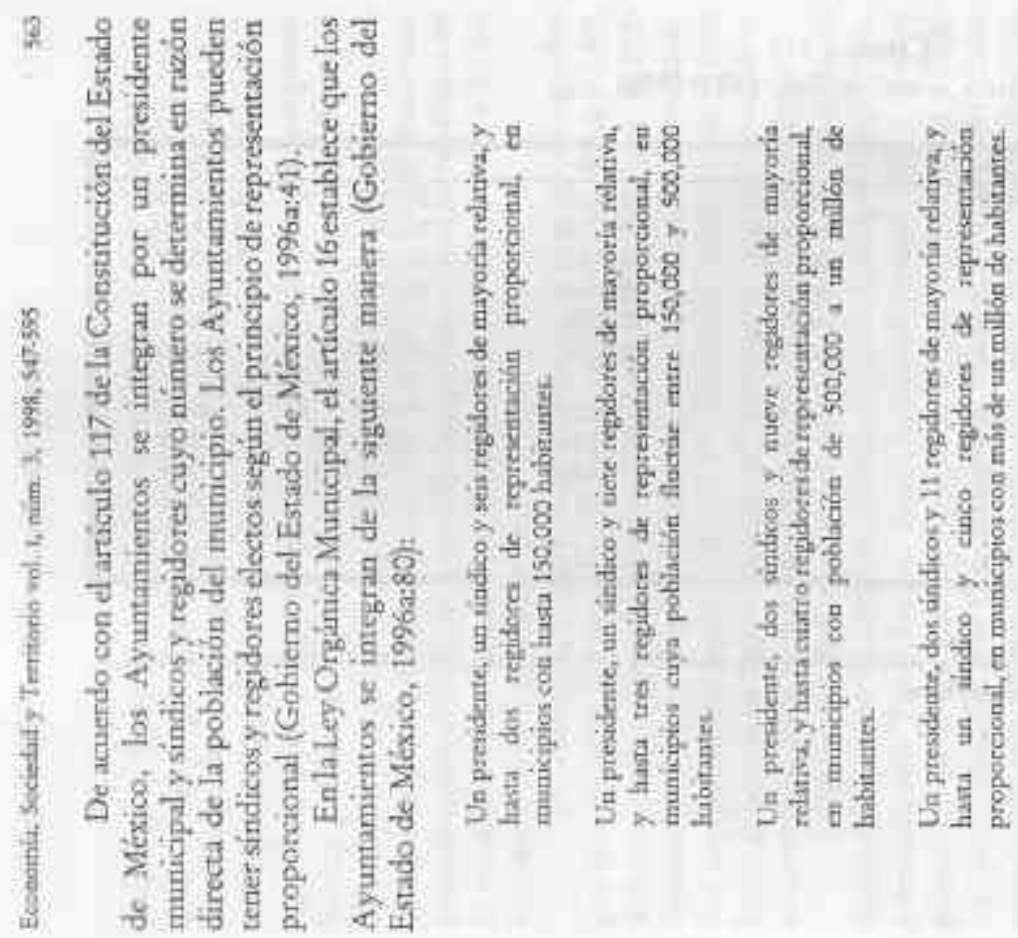

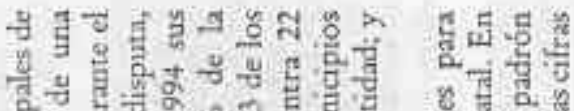

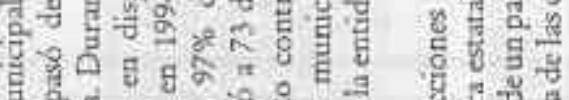

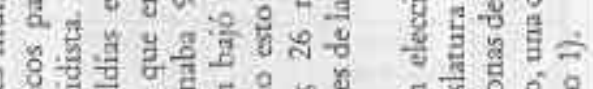

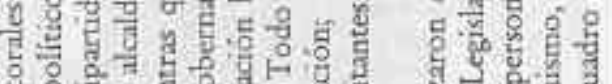

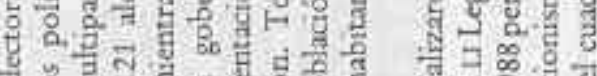

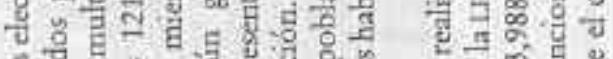
g象 5. 음 긍

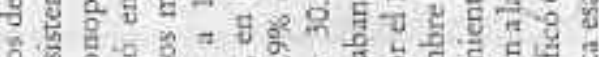

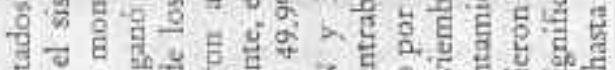

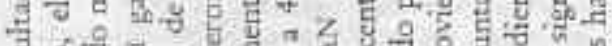

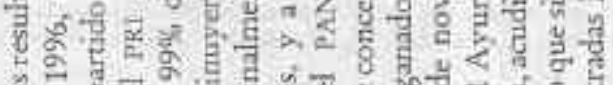

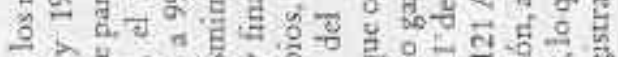

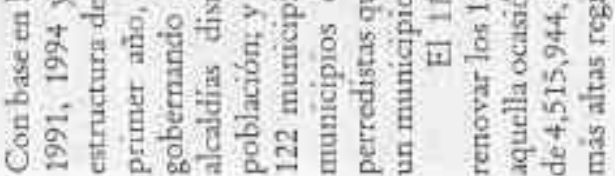

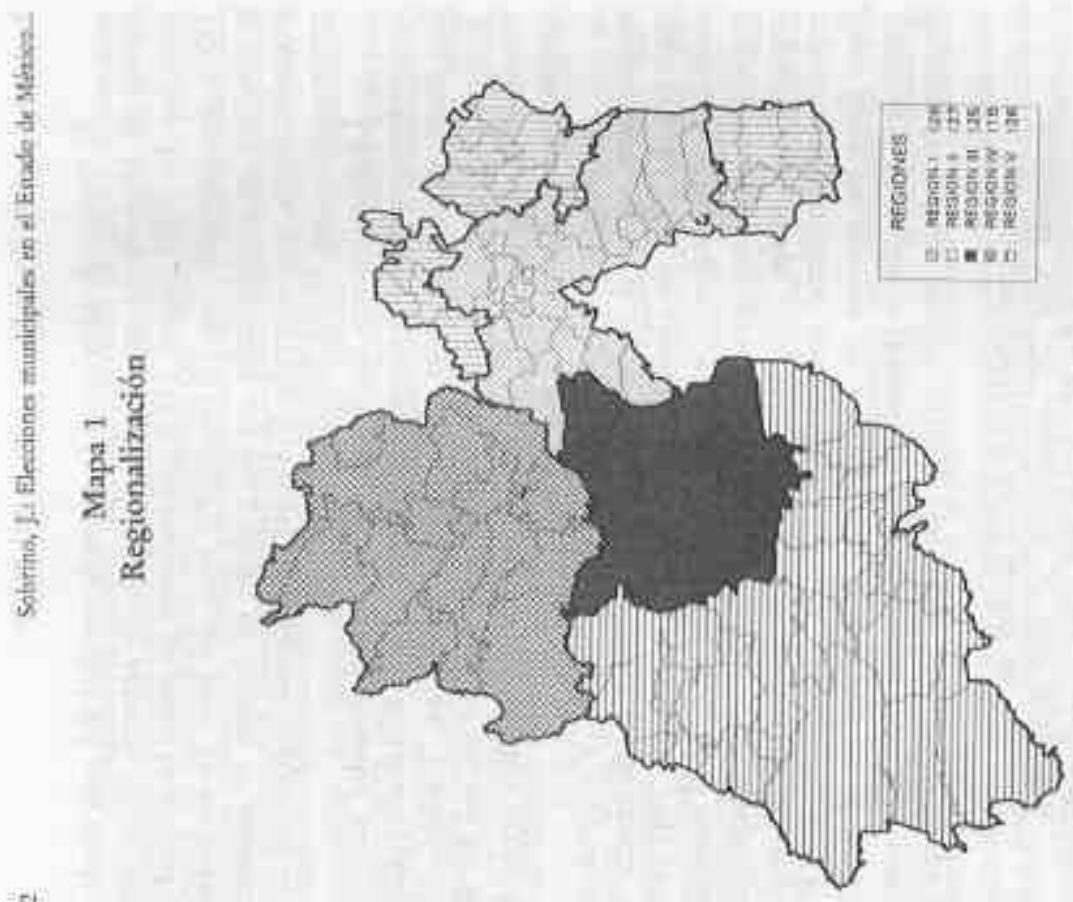




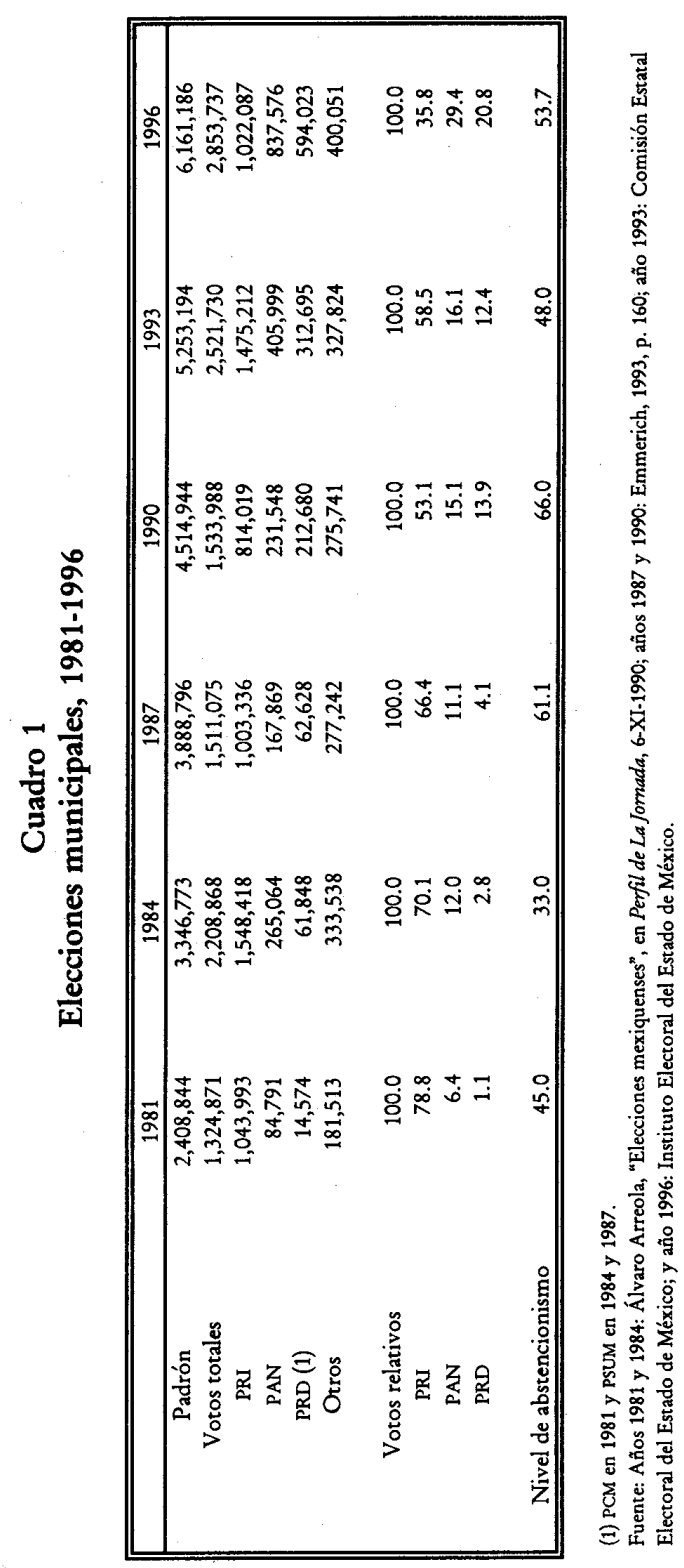

$\mathrm{Al}$ contabilizar los votos totales emitidos, $53.1 \%$ estaban cruzados en favor de: PRI, $15.1 \%$; PAN, $13.9 \%$; PRD y otros partidos, nulos y no registrados, $17.9 \%$. Cabe mencionar que por primera ocasión en elecciones municipales el PRI obtuvo menos de $60 \%$ de los sufragios totales, el PAN mostró un avance modesto, y el PRD elevó significativamente su participación, al grado de casi ocupar la segunda fuerza política de la entidad desde el punto de vista de votos obtenidos. Es indudable que el PRD aprovechó, de alguna manera, los resultados tan favorables obtenidos por el FDN en las elecciones presidenciales de 1988, aunque habría esperado un mejor resultado en la medida en que durante esa elección el FDN obtuvo $48.4 \%$ de los sufragios, contra $28.4 \%$ del PRI.

Sin embargo, el poco más de $50 \%$ de los votos conseguidos por el PRI fueron suficientes para ganar 116 de las 121 alcaldías $(95.9 \%$ de los municipios), en donde vivía $99 \%$ de la población estatal. El PRD obtuvolos Ayuntamientos de Tequixquiac, Cocotitlán y Chiconcuac, con una población equivalente a $0.4 \%$ del estado, mientras que el PAN logró gobernar en San Martín de las Pirámides y Cuautitlán, donde se concentraba $0.6 \%$ de los habitantes de la entidad (véase el mapa 2).

Los resultados electorales fueron impugnados en algunos municipios como Cocotitlán, Jalatlaco, Isidro Fabela y Xonacailán, sobresaliendo Tejupilco, en donde la inconformidad inició con un plantón el 14 de noviembre, siguió con bloqueos a carreteras y llegó a su punto más álgido el 12 de diciembre, cuando policías y perredistas protagonizaron un enfrentamiento armado. Los hechos sangrientos ocasionaron la renuncia del presidente municipal prísta y la instauración de un concejo presidido también por un miembro del PRI (La Jornada, 2-I-1991 y Proceso, núm. 737, 1990).

A nivel regional, de los cinco municipios en manos de la oposición, uno era de la región I y los cuatro restantes de la II. Cuautitlán fue el municipio más importante en términos económicodemográficos en poder de la oposición, mientras que la mayor lucha relativa ocurrió en la región II, conformada por municipios del oriente del estado y circundantes a los metropolitanos. En esta región el PRI gobernaba $87.3 \%$ de los habitantes, contra $9.6 \%$ del PRD y $3.1 \%$ del PAN. A pesar de los logros electorales de la oposición, el sistema de partidos en dicha región seguía siendo del tipo de partido monopolista.

En un estudio realizado para analizar la geografía electoral del proceso, se llegó a la conclusión de que los votos para el PRI fueron relativamente menores en municipios más urbanizados, industrializados y densamente poblados. La votación prísta tendía a 

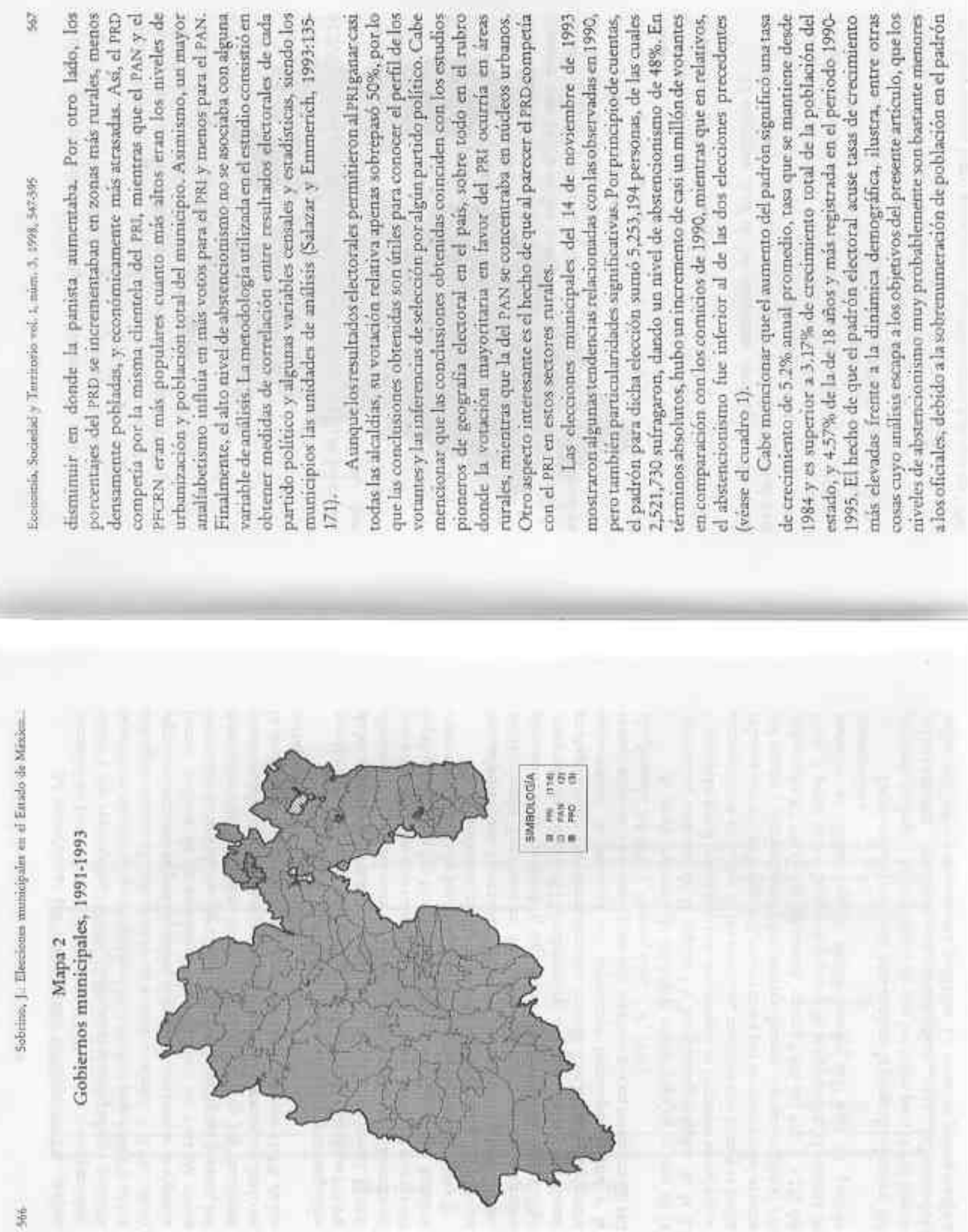

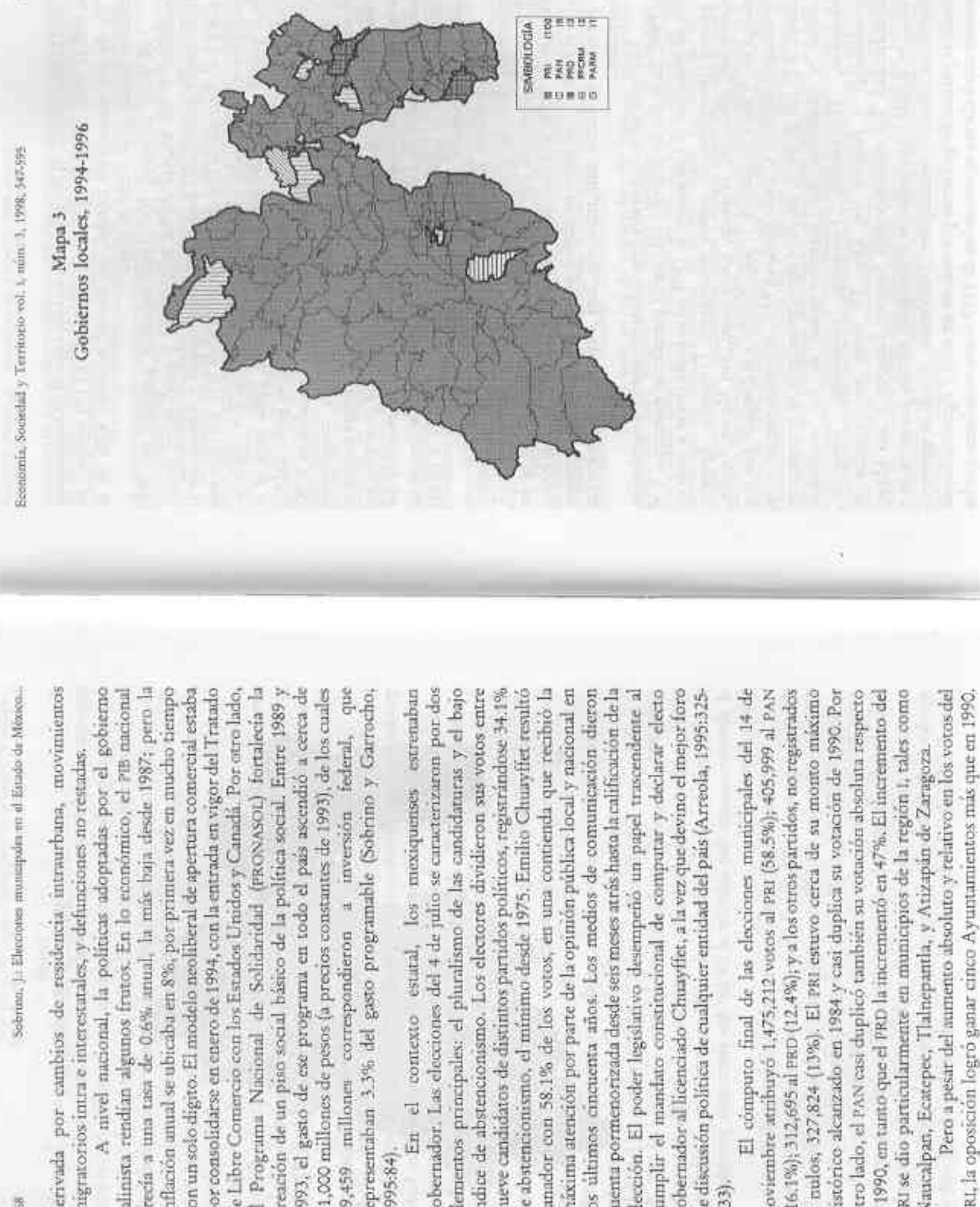

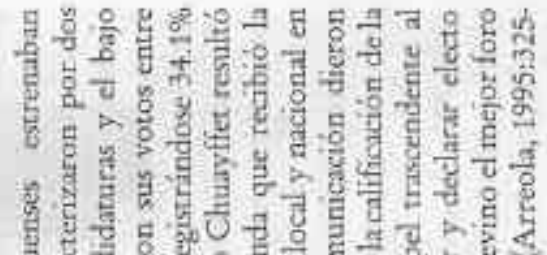

3 둥

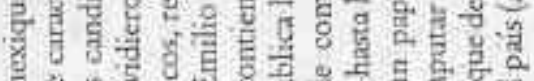

音

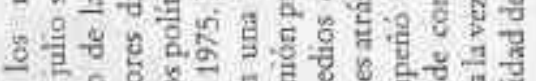
- 을 8 ज

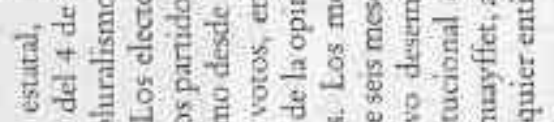

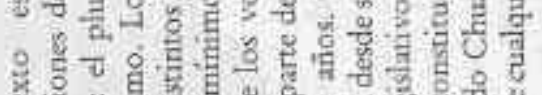

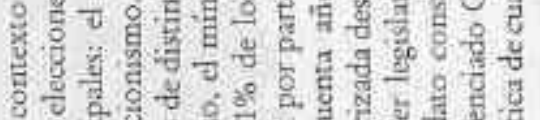
๘

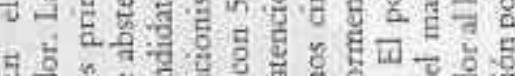

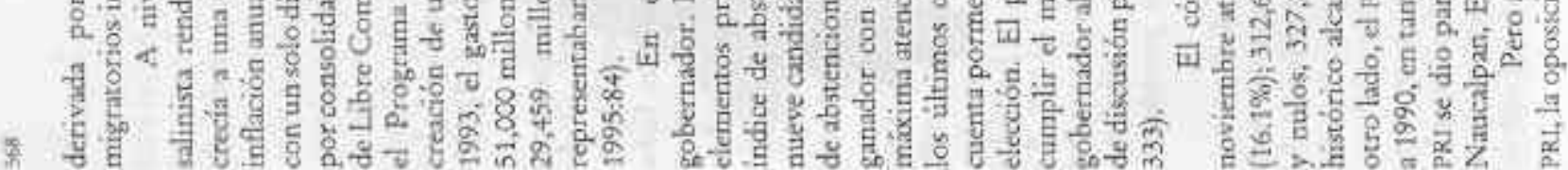

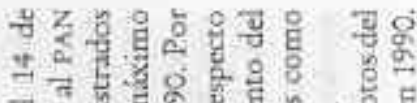
궁

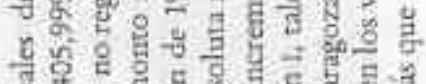
त.

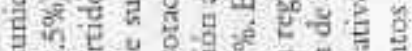
E $\frac{\pi}{2}$.

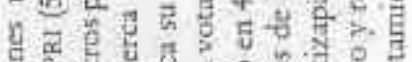
过 के है

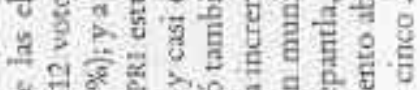

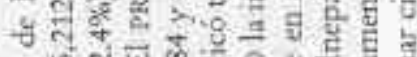

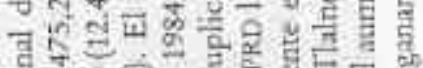
I - 8 g

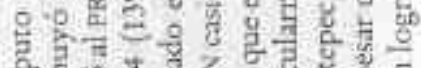

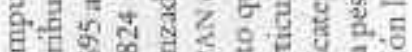

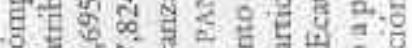


De los 121 municipios, el PRI ganó 109, en tanto que el PAN conquistó seis, tres el PRD, dos el PFCRN, y uno el PARM. El PRI dominó en $90.1 \%$ de los municipios totales, en donde habitaba $97 \%$ de la población mexiquense (véase el mapa 3).

El PAN conservó los Ayuntamientos ganados en 1990 (Cuautitlán y San Martín de las Pirámides), y ganó otros cuatro anteriormente gobernados por el PRI: Tepotzotlán y Atenco, de la región I; San Antonio la Isla, de la III; y Aculco, de la IV. En estos seis municipios se concentraba $1.7 \%$ de la población estatal. Por otro lado, el PRD perdió en los tres municipios ganados en 1990, pero se le reconocieron triunfos en otros tres que estaban antes en poder del PRI y que se encuentran contiguos o cercanos a los gobernados en 1990 Coyotepec, Juchitepec y Tepetlaoxtoc. Estos tres municipios pertenecen a la región II, por lo que se mantuvo la presencia exclusiva de dicho partido en tal ámbito territorial del estado. En conjunto, los tres municipios participaban con $0.6 \%$ de la población estimada del estado al 1 de enero de 1994. El PFCRN ganó los Ayuntamientos de Chapultepec, de la región III, y Villa Guerrero, de la V; el PARM triunfó en Huehuetoca, de la región II.

Los resultados electorales mostraron avance de una mayor competencia electoral en la región II, ya que de su población total, $78.3 \%$ quedó gobernada por el PRI (contra $87.3 \%$ conseguido en las elecciones de 1990), en tanto que el PRD presidía $12.6 \%, 6.0 \%$ el PARM y $3.1 \%$ el PAN. Si bien hubo un mayor pluralismo, el sistema regional de partidos políticos aún mostraba una estructura de partidos monopolista.

Los resultados electorales fueron más impugnados en relación con 1990. La toma de protesta del nuevo presidente municipal y el inicio de gestiones el 1 de enero de 1994 no se pudo llevar a cabo en el palacio municipal de nueve municipios (Texcoco, Apaxco, Tequixquiac, Atizapán, Jalatlaco, Ocoyoacac, San Mateo Atenco, Tenango del Valle e Ixtapan de la Sal), debido a la toma de éste por simpatizantes del PRD, Círculo Blanco y PAN, derrotados según cifras oficiales. A la par de éstos, en otros siete municipios se presentaron protestas y plantones por inconformidad de los resultados: Teoloyucan, Tlalmanalco, Calimaya, Joquicingo, Jiquipilco, Temascalcingo e Ixtapan del Oro. De estos movimientos de inconformidad, los más relevantes fueron: Texcoco y San Mateo Atenco, en donde los presidentes municipales electos renunciaron y se formaron concejos municipales; Ocoyoacac, donde se mantuvo tomado el palacio de gobierno por más de un año; y Apaxco, donde se suscitó una balacera en diciembre de 1993. Cabe mencionar que las acciones de inconformidad ocurrieron principalmente en municipios de la región del valle de Toluca, comandados por simpatizantes del Círculo Blanco (El Sol de Toluca, 1 a 15-I-1994).

El comportamiento electoral de la población mexiquense no observó grandes cambios respecto a lo mostrado en las elecciones municipales de 1990, y estatales del año de 1993. Además de los seis Ayuntamientos ganados, el PAN mostró una presencia mayor respecto al promedio estatal en la parte norte y occidente de la región de municipios metropolitanos, así como en municipios contiguos a Querétaro, de la región II, y en la parte oriental de la región del valle de Toluca. El PRD tuvo una presencia relativa más importante en la región II, sur de la región III, y municipios de la región IV colindantes con Michoacán. El PRI mantuvo su predominio casi exclusivo en municipios predominantemente rurales de las regiones III, IV y $\mathrm{v}$, además de mejorar su imagen en los más importantes dentro de los municipios metropolitanos de la ciudad de México.

El PAN siguió recabando mayor votación relativa en municipios de mayor urbanización, desarrollo y calidad de servicios, mientras que el PRI y en menor medida el PRD gozaron de mayor popularidad en comunidades rurales con escasos servicios. Una de las características del proceso electoral en municipios rurales fue el mayor margen de maniobra electoral y manipulación de resultados por parte del partido en el poder. Finalmente, no se observó relación entre abstencionismo y otras variables, por lo que éste se distribuyó de manera más o menos homogénea en las cinco regiones de la entidad (Arenas, Bahena y Sánchez, 1995:95-119).

Una vez más, el 10 de noviembre de 1996 se desarrollaron elecciones para renovar 122 Ayuntamientos y la LII Legislatura, compuesta ahora por 75 escaños en vez de los 66 anteriores. Estas elecciones se caracterizaron, en primer lugar, por estrenar nuevas reglas electorales contenidas en el Código Electoral del Estado de México (Gobierno del Estado de México, 1996b), aprobado el 2 de marzo de 1996, el cual abrogó a la Ley de Organizaciones Políticas y Procedimientos Electorales del Estado de México, expedido en abril de 1978 y que contenía reformas y adiciones hasta 1993. La Ley de organizaciones políticas se encontraba muy rezagada respecto a las innovaciones en materia electoral del COFIPE, por lo que la estructura y el contenido de este nuevo código se ajustó más a la legislación federal, obteniéndose un documento similar, aunque no idéntico, respecto al COFIPE y muy cercano a las legislaciones de los estados de Durango y Zacatecas. 
El Código estatal presenta dos avances respecto al Compet la destgnacion del presudente del Consejo Electoral por parte dela Legisharura del efrado (articulo 86, fracción 1); y los límites a la representación parlamentaria del partido mayoritario (artículo 265) Cabe destacar que este úlrimo avance contiene cambios significativos respecto a los articulos $179,179-\mathrm{A}, 179-\mathrm{B}, 179-\mathrm{C}$ y $179-\mathrm{D}$ dela antizua Ley (Gobierno del Estado de México, 1993b:86-89) vigente hasta el primero de marzo de 1996, La aplicación de estas inneyaciones dectorales impósibilitaron al pRa contar con una mavoria en el Congreso local al no adjudicirsele diputados de representación priporcional, según el fallo enitido por el Tribund Estatal Electoral d) 4 de diciembre de 1996 y que trajo como conseentencia un Congreso conformado por 30 diputados del PRT, 22 del PAN, 16 del PRD, euatro del PVEM, dos del Pi y uno del PC.

Entre algunas de las insuficiencias del Código estatal respecto al federal, figura la inexistencia de una sala de segunda instancia en la que las partes en litigio podrian impugrar un dictamen original del Tribunal Electoral, 15 pecto que aparcee en 12 legislaciones estatales (Crespo, 1996:148-151). Al no existir dicha sala, no procedió recurso alguno contra las resoluciones del Tribunal.

El padrónelectoral (o lista nominal) part estos comicios sumé $6,161,186$ personis, lo que significaba una rasa de crecimiento anual promedio de $5.49 \%$ con respecto al padrón de 1993, nuevamente por encima de la dinàmica demográfica estatal $(3.17 \%$ en el periodo 1990. 1995) y de la población de 18 años $y$ mas $(4.5796)$.

De ba lista nominal, $2,853,737$ personas acudieron a las urnas para elegir a sus gobiernos locales, lo que representó un aivel de abstencionismo de $537 \%$. Estos comicios han sido los más concurridos en términos absolutos hasta el momento, superando por 332,007 votos a los de 1993 , y con el segundo menot nivel de abstencionismo de los ültimes nueve at̃os:

A diferencia de lis dos clecciones anteriores, los niveles de abstencionismo no se distribuyeron de manera homogénea a lo largo del territorio, por lo que se le pueden asociar algunas variables socioeconnimicas. La región que observó una menor participación relativa fue la de los municipios metropolitanos de las cindad de México, con $57.6 \%$ de abstencionismo, mientras que el mayor aforo deurrió en los municipios metropolitanos no conurbados, con 40.19 deabstencionismo, seguidos por los municipios del sur del estado, con 41.9\%. Las regiones del valle de Toluca y norte del estado tuvieron 44.9 y $45.4 \%$, respectivamente

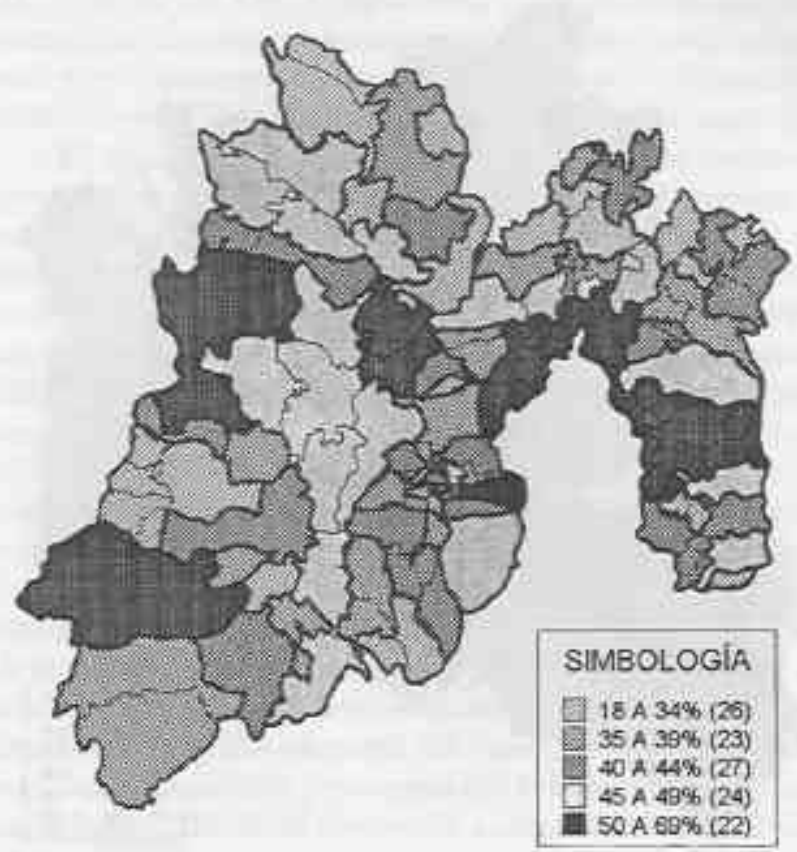




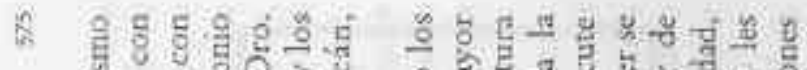

至

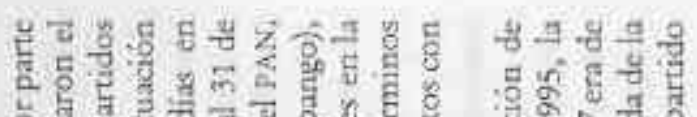

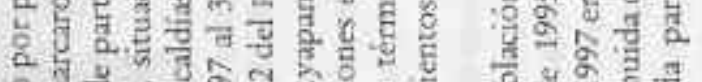

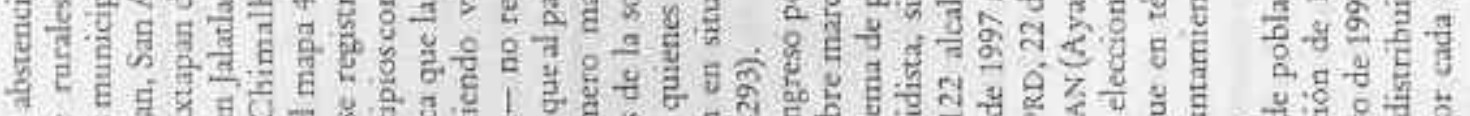
प्रे

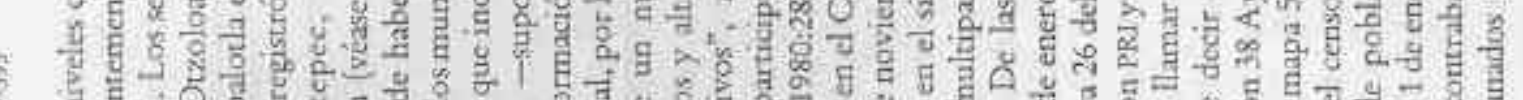
क द्व

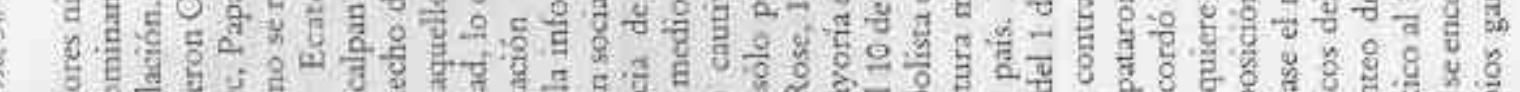
E

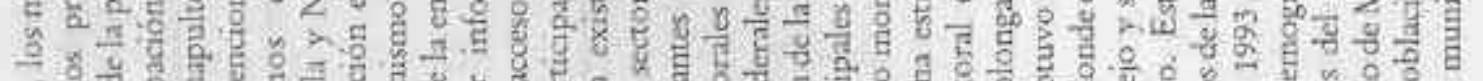
त 等

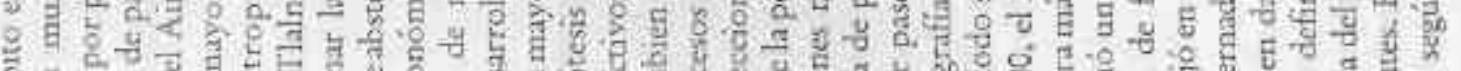

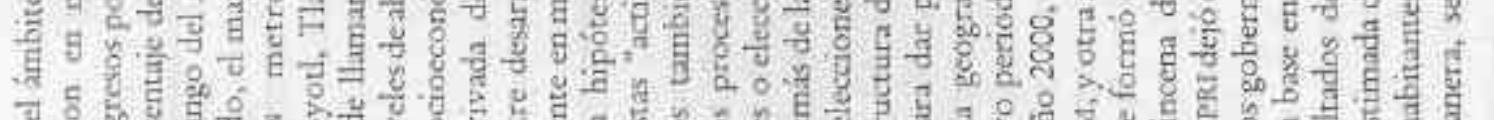
J

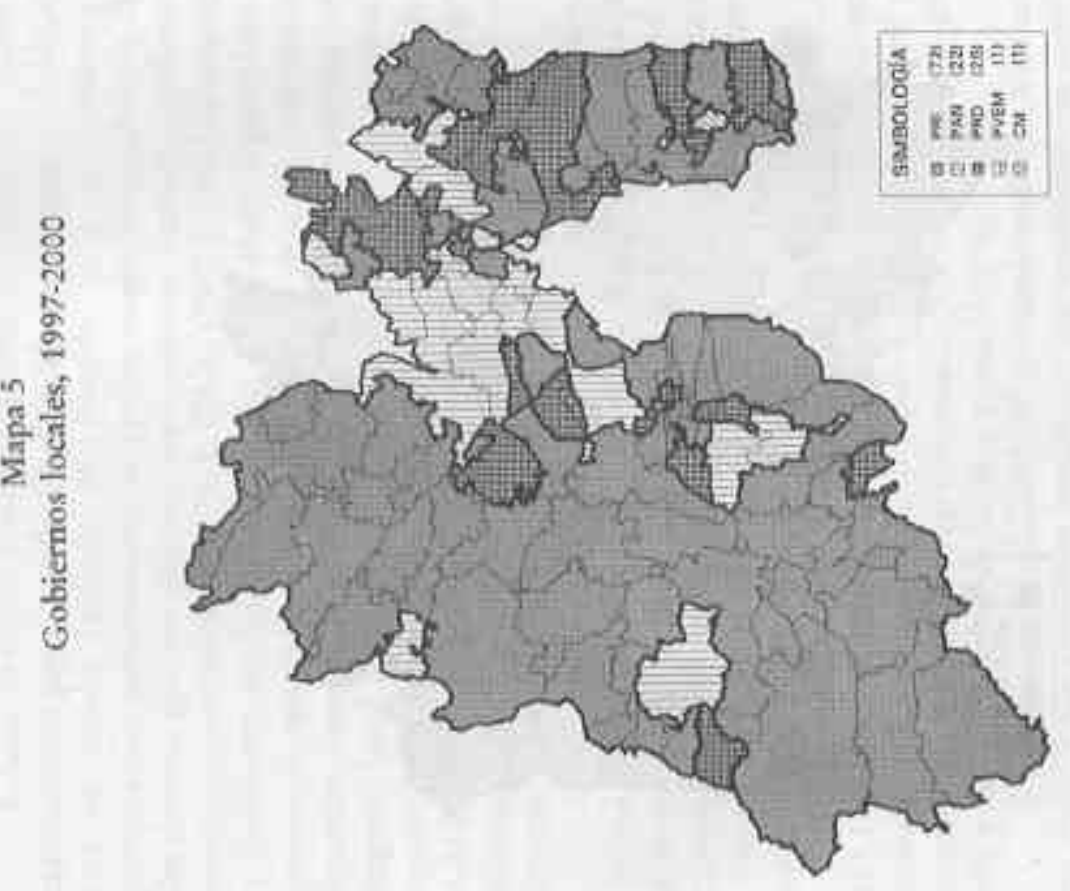


Cuadro 2

Municipios y población por partido político, 1997

\begin{tabular}{|cccc||}
\hline Partidos & Municipios & $\begin{array}{c}\text { Población } \\
\text { absoluta }\end{array}$ & $\begin{array}{c}\text { Población } \\
\text { relativa }\end{array}$ \\
\hline Total & 122 & $12^{\prime} 168,654$ & 100.00 \\
PRI & 72 & $6^{\prime} 073,130$ & 49.91 \\
PAN & 22 & $3^{\prime} 688,467$ & 30.31 \\
PRD & 26 & $2^{\prime} 392,498$ & 19.66 \\
PVEM & 1 & 9,563 & 0.08 \\
CM & 1 & 4,996 & 0.04 \\
\hline
\end{tabular}

La dinámica de las elecciones locales ocurrió de la siguiente manera: de los 109 municipios con que contaba el PRI en 1993, conservó 65, perdió 44, recuperó seis que estaban en manos de la oposición (Aculco, Atenco y San Antonio la Isla, del PAN; Juchitepec, del PRD; y Chapultepec y Villa Guerrero, del PFCRN), y ganó las primeras elecciones del municipio de Valle de Chalco Solidaridad. Por su parte, Acción Nacional conservó tres de los seis que tenía (Cuautitlán, San Martín de las Pirámides y Tepotzotlán), perdió los otros tres a manos del PRI, y ganó a éste 17 municipios, uno al PRD (Coyotepec) y el del PARM (Huehuetoca). El PRD conservó Tepetlaoxtoc por apenas dos votos de diferencia y perdió los otrós dos que gobernaba, pero a cambio obtuvo 25 municipios que pertenecían al PRI. Finalmente, los municipios de Cocotitlán (ganado por el PVEM) y Ayapango tenían un gobierno local prísta. Los estudios de geografía electoral realizados hasta antes de esta elección, describieron el comportamiento electoral de la población con base en la relación estadística entre ciertas variables socioeconómicas y el porcentaje de votación obtenido por cada partido político. Con los resultados de esta elección, dicho comportamiento se puede analizar ahora tomando en cuenta tanto el método anterior, como las características de los municipios ganados por cada partido político.

De la votación total emitida en los 122 municipios $(2,853,737)$, el PRI obtuvo 1,022,087, equivalentes a $35.82 \% ; 453,125$ votos menos que en 1993 y el segundo porcentaje más bajo en todo tipo de elecciones en la historia contemporánea, sólo superior por siete puntos porcentuales al conseguido por Carlos Salinas de Gortari en las elecciones presidenciales del 6 de julio de 1988. En términos generales, el PRI obtuvo un mayor porcentaje entre la población ocupada en actividades agropecuarias, niveles de ingreso predominantemente por abajo de dos salarios mínimos mensuales, mayor índice de carencias de satisfactores colectivos (agua potable, drenaje, energía eléctrica, educación y salud), y en municipios con mayores tasas de emigración y mayor gasto per cápita por parte del PRONASOL durante 1989-1993. $\mathrm{Si}$ bien no existió relación estadística entre abstencionismo y porcentaje de votos para el partido oficial, en todas las regiones los municipios conseguidos por el PRI tuvieron un mayor promedio de abstencionismo repecto a los ganados por la oposición.

En términos demográficos, los municipios más importantes conseguidos por el PRI fueron Ecatepec (el más poblado de la entidad y tercero a nivel nacional, sólo por abajo de la delegación Iztapalapa del Distrito Federal y Guadalajara, según datos definitivos del conteo de población de 1995), Toluca, Chimalhuacán, Valle de Chalco Solidaridad y Tultitlán.

De los 50 municipios en donde no ganó el PRI, sólo en Tultepec quedó en tercer lugar, mientras que en los otros 49 fue segundo. Respecto a los 72 municipios conseguidos por este partido, el PAN quedó en segundo lugar en 43, el PRD en 21 y en cuatro el PPM y $\mathrm{PC}$, respectivamente.

Los municipios prístas fueron ganados por un margen promedio de 19.25 puntos porcentuales respecto a los votos relativos del segundo partido político. Los triunfos más apretados ocurrieron en Nextlalpan, con 0.79; Villa Guerrero, con 1.52; Toluca, con 1.99; Atenco, con 2.06; y Amecameca, con 2.53 puntos porcentuales (véase el mapa 6). En el polo opuesto, Jocotitlán fue donde se obtuvo el mayor margen, con 49.05, seguido por San Simón de Guerrero, Donato Guerra, Villa de Allende, y Jalatlaco.

Por lo que respecta al PAN, sus votos en el estado sumaron 837,576 , que representaron $29.35 \%$ del total. Con relación a los resultados de 1993, este partido mostró el mayor avance al duplicar su votación en números absolutos y aumentar 13.3 puntos porcentuales su participación relativa, con lo que se consolidó como la segunda fuerza política de la entidad. El PAN obtuvo mayores porcentajes de votación entre la población ocupada en actividades del sector industrial, sueldos superiores a dos veces el salario mínimc mensual, menores índices de carencias de satisfactores colectivos, y municipios con menor gasto per cápita del PRONASOL. Esto significa que, tal y como ocurrió en las dos elecciones anteriores, los votos del PAN tendieron a aumentar donde los del PRI disminuían, por lo que se 
manifestó con mayor cluridad la dicotomía PAN urbano-PBS rural. EI nivel de abstencionismo no tuvo relación con el porcent uje de vatos para el PAN, por to que el promedio de abstencionismo en los municipios donde ganó fue similar al experimentado por el giobal ertatal.

De los 22 municipios conseztidos, los más importantes por tamario de población y concentración de actividades económicas fueron Nancalpan, Thalnepartla, Arizapán de Zaragoza, Cuautitlàn Izcalli y Nicolás Romero, todos pertenecientes a la region I. En los 22 municipios se genera más de $55 \%$ del FiB tocal de luentidad, por lo que su generación de valor anivel nacional solo es superada porel Distrito Federal y los estados de Jalisco y Nuevo Leon.

El margen de diferencia promedio de los municipios ganados por el PAN fur de 14.19 puntos poreentules, lo que infica que las clecciones en estos 22 municipios fueron, en términos generales, más competidas respecto a aquellas en donde se impuso el PRI. Los municipios con menor diferencia fueron: Tenango del Valle, con 1.44; El Oro, con 3.48; ; Tlainepantla, con 3.66. Por otro lado, Tenancingo montró el mayor margen con 28.47 , seguido por Apaxco y Valle de Bravo (vease el mapa 6).

Finalmente, el PRD logró 594,023 votos que significaron $20.82 \%$, casi duplicundo sus votos absolutos e incrementando ocho puntos porcentuales su participación relativa en comparación con lo ocarrido en 1993. A diferencia de las dos elecciones anteriores, el porcentaje de voros logrados en carda municipio no etuvo asociado con alguna curncteristica sociocconúmica de la población; situación. que también ise percibió en las elecciontes presidenciales de 1988 (Graizbord y Sobrino, 1990:235), por lo que obtuvo votos: indistintamente del ámbito urbano y rural, en municipios atractores y expulsores de población, favorecida por un electomado preferentemente joven, con ingresos superiores al los de simparizantes del pRten el area rural, yocupados en actividades terciarias y subempleo en areas urbanas con menores ingresos respecto a los seguidores del PAN. En otras palabras, sectores sociales turales menos marginados y habitantes. de colonias urbano-populares.

De acuerdo con el tamario de población, los municipios perredist is mas importantes fueron Nezahualóbyotl (quinto a nive) nacional), La Paz, Texcoco, Zumpanga y Tultepec, todos dela región f. Los 26 municipios en donde el PRD obtuvo el triunfo se caracterizaron por presentar, en promedio, el menor nivel de abstencionismo (41.13\%) y la menor diferencia relativa respecto al segundo partido con mayor votación $(9,33)$. Esto indica que el pRD

Mapa 6

Margen de victoria, 1996

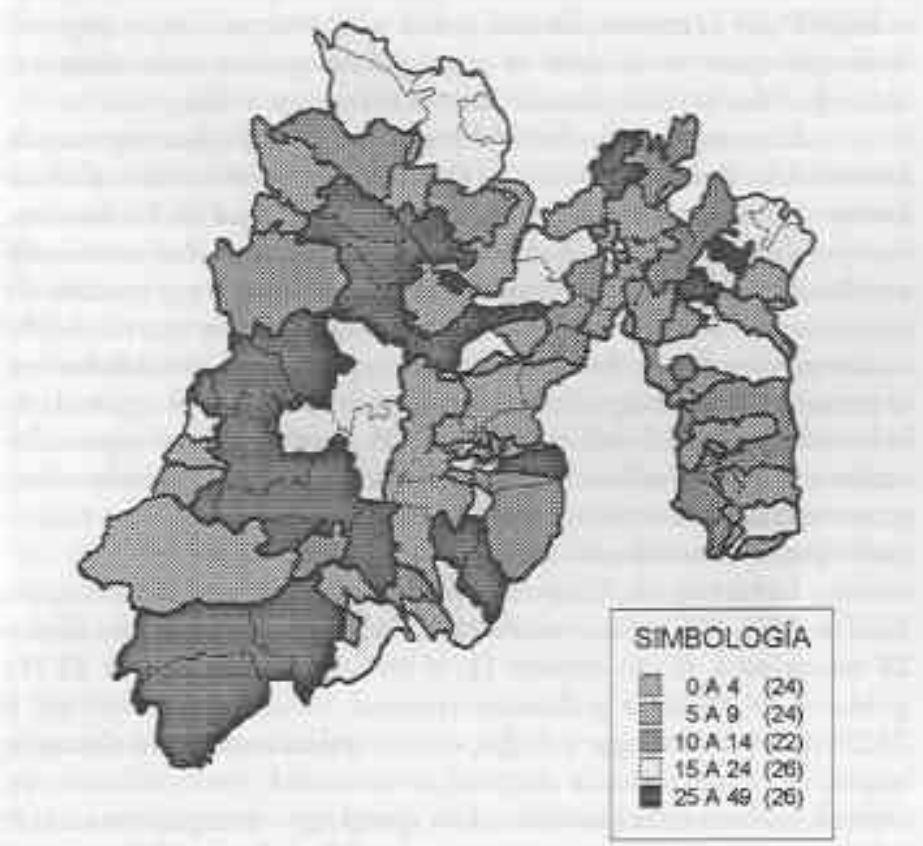


logró ganar ante elecciones concurridas y competidas, tal y como ocurrió en Tepetlaoxtoc, donde ganó por sólo dos votos $(0.03$ puntos porcentuales), Otzoloapan por 22 (1.26), Xonacatlán por $37(0.30)$, y Tonatico por 79 (1.86).

Las relaciones anteriores establecen que el PRD dejó de competir por la misma clientela política del PRI, por lo que se puede definir con mayor claridad el perfil del comportamiento electoral individual hacia cualquiera de las tres fuerzas políticas.

La competencia electoral fue distinta en las cinco regiones de la entidad. Por principio de cuentas, no existió una relación contundente entre abstencionismo y resultado final de la elección, aunque sí se percibió una cierta relación entre mayor abstencionismo con triunfo del PRI en la región I, mayor participación y triunfos de la oposición en la región II, y mayor participación con triunfo del PRI en las regiones IV y V. Esto significa que la participación ciudadana en el proceso electoral tuvo diferencias significativas a nivel regional, no sólo en la cantidad de votantes sino en el comportamiento expresado: en los municipios urbanos y metropolitanos, a mayor participación, mayores triunfos de la oposición; en municipios rurales, a mayor participación, menores triunfos de la oposición.

La región I se compone de 28 municipios con una población total de 8,526,906 habitantes, $70.1 \%$ de la población del estado. De los 28 municipios, el PRI obtuvo 11, el PAN 10, y siete el PRD. El PRI gobierna $39.9 \%$ de la población regional, contra $37.9 \%$ del PAN y $22.2 \%$ del PRD. Sin lugar a dudas, en esta región se presentó el mayor avance en la competencia electoral de la entidad, conformándose un sistema político multipartidista en el que el PAN consiguió una mejor posición al triunfar, entre otros, en Naucalpan, Tlalnepantla, Cuautitlán Izcalli y Atizapán de Zaragoza, mientras que el PRD obtuvo las alcaldías de Nezahualcóyotl y Texcoco.

Las tendencias competitivas en la región II de las dos elecciones anteriores se consolidaron en esta elección. De los 27 municipios en juego, el PRI ganó 11, contra ocho del PRD, seis del PAN, uno el PVEM, y el empate en Ayapango entre el PRI y PAN con 789 votos cada uno. En esta región el PRI gobierna $36.7 \%$ de la población, el PRD $36.4 \%$ y $24.6 \%$ el PAN. El PRD se consolidó como la segunda fuerza política regional, con una cobertura muy cercana a la del partido oficial.

En las regiones III, IV y $\mathrm{V}$, el sistema político se sigue caracterizando por una estructura de partido monopolista, no obstante que la oposición mostró un avance significativo, pues el PAN compitió afanosamente en Toluca y Metepec, a la vez que ganó con

facilidad Tenancingo y Lerma, en tanto que el PRD se impuso en San Mateo Atenco, Jiquipilco y Otzolotepec, entre otros.

Los resultados oficiales de estas elecciones no causaron polémica e incluso los líderes nacionales del PAN y PRD reconocieron que habían sido las más limpias y transparentes en toda la historia de los procesos electorales de la entidad (Reforma, 13-XI-1996). Los simpatizantes priístas del grupo de los "siete magníficos" de Nezahualcóyotl intentaron movilizaciones en protesta por un supuesto fraude electoral sin tener resultado alguno, ya que incluso en la dirigencia nacional se reconoció la derrota por el hecho de haberse seleccionado a un candidato sin "arrastre" y poder de convocatoria. Por otro lado, en los municipios de Chicoloapan, Tejupilco y Tepetlaoxtoc, la protesta del nuevo presidente no se llevó a cabo en el palacio municipal debido a la toma de éste por perredistas en los dos primeros municipios, y de prístas en el tercero. Tras el empate, en Ayapango se formó un concejo integrado por tres panistas, tres priistas y un perredista. En Nextlalpan los panistas pidieron el esclarecimiento de la muerte del primo del ex candidato y la revisión del cómputo de los votos. Todos los movimientos terminaron antes del 10 de enero de 1997, salvo en Tejupilco, donde los perredistas desalojaron el palacio municipal hasta el 15 de enero tras obtener varias responsabilidades administrativas.

\section{A manera de conclusión}

1. Los estudios sobre geografía de las elecciones locales son de suma importancia para establecer asociaciones estadísticas entre el comportamiento electoral de los individuos frente al espectro político que se les presenta. Un estudio apoyado en series de tiempo permite inferir también la evaluación, aprobación o el castigo hacia el desempeño de las funciones de los gobiernos municipales.

2. El comportamiento electoral en procesos locales no responde necesariamente a categorías nacionales, por lo que es necesario introducir aspectos coyunturales derivados del territorio municipal en donde se suscitan, así como grupos políticos locales y personalidad, imagen y trayectoria de los candidatos a ocupar puestos de elección popular. Uno de los aspectos que incide en el proceso electoral de varios municipios es la presencia de grupos o caciques locales que han permanecido en el poder durante varios años. En la elección de 1996, los viejos caciques aplicaron novedosas estrategias para sostenerse en 
el poder, mientras que los nuevos lo hicieron para remplazar a los anteriores. La mayoría de estas novedosas estrategias se basaron en el establecimiento de alianzas con partidos de oposición (Reforma, 20-I1997:4A).

3. La revisión efectuada a las tres últimas elecciones municipales en el Estado de México mostró un cambio significativo en la estructura y dinámica del sistema de partidos políticos, siendo la característica principal el cambio de una estructura de partido monopolista, a otra multipartidista, situación inédita hasta ese momento en la geografía electoral del país.

4. El avance sin precedente de la oposición, al ganar 49 de las 122 alcaldías en disputa el 10 de noviembre de 1996, significa una recomposición de fuerzas políticas dentro de la entidad, el desmembramiento de los círculos de poder priísta, su asociación en algunos casos con partidos de oposición, y la consolidación de perfiles en el comportamiento electoral de la población. Es necesario que dicha recomposición política sea secundada y afirmada por el ejercicio de funciones de gobierno local más eficiente y con mayor equidad. Así, la posibilidad está abierta para impulsar acciones innovadoras en la administración y gestión pública a partir de una mayor apertura a la participación ciudadana.

5. La estructura multipartidista de los gobiernos locales significa también, retos y oportunidades para las relaciones intergubernamentales. Es indudable que el gobierno estatal deberá actuar con mayor cautela y eficiencia, con el fin de garantizar la gobernabilidad de la entidad y la solución de conflictos sociales. Por lo pronto, en Naucalpan y Nezahualcóyotl ya se han suscitado problemas entre agentes vinculados con el partido oficial y las nuevas autoridades.

6. Se mencionó que las elecciones del 10 de noviembre de 1996 representaron un laboratorio de lo que podría ocurrir en los comicios de 1997. De haber sido así, en las elecciones para elegir al primer jefe de gobierno del Distrito Federal se hubiera esperado un proceso electoral caracterizado por un elevado nivel de abstencionismo y un triunfo muy apretado del PAN, tal y como que se presentó en el proceso electoral del 10 de noviembre de 1996 en los cuatro municipios metropolitanos de mayor interrelación con la capital del país: Naucalpan, Tlalnepantla, Ecatepec y Nezahualcóyotl, en donde se registró $61.8 \%$ de abstencionismo y el PAN obtuvo la mayor votación, pero sólo por tres votos de diferencia respecto al PRI $(292,883$ contra 292,880$)$

Sin embargo, trasladar estos resultados al Distrito Federal implicaría caer en una falacia ecológica, muy típica en estudios de geografía electoral, ya que el contexto local, social, político y coyuntural de ambas elecciones es significativamente diferente, tal y como se demostró con los resultados finales del proceso electoral del 6 de julio de 1997, tanto en lo que respecta a la elección del jefe de gobierno del Distrito Federal, como la de diputados federales del Estado de México.

7. Finalmente, la estructura multipartidista es sinónimo de cambios en el partido gobernante, o alternancia en el poder. Es de llamar la atención que en el Estado de México, tan solo cuatro municipios, Cuautitlán, San Martín de las Pirámides, Tepetlaoxtoc y Tepotzotlán, han conservado un gobierno local de oposición en dos o más periodos consecutivos, mientras que tres han experimentado una alternancia de poder: Coyotepec (PRI-PRD-PAN), Huehuetoca (PRI-PARM-PAN) y Cocotitlán (PRD-PRI-PVEM). Si efectivamente existe ya un perfil definido en el comportamiento electoral de la población mexiquense, se esperaría que el PAN y el PRD conserven para las elecciones de julio del año 2000 lo que han conseguido hasta ahora. Pero lo más probable sería un cambio en gran cantidad de alcaldías, y no necesariamente que regresaran al PRI. El contexto local será algo definitivo en este sentido. El desempeño de los actuales Ayuntamientos lo decidirá. La recomposición de las fuerzas políticas lo esclarecerá. El tiempo lo dirá. 
Cuadro anexo

Población estimada y región

\begin{tabular}{|c|c|c|c|c|}
\hline \multirow[t]{2}{*}{ MUNICIPIO } & \multicolumn{3}{|c|}{ POBLACIÓN ESTIMADA } & \multirow[t]{2}{*}{ REGIÓN } \\
\hline & 1991 & 1994 & 1997 & \\
\hline ESTADO DE MÉXICO & $10,055,453$ & $11,031,767$ & $12,168,654$ & \\
\hline 1 ACAMBAY & 48,223 & 50,928 & 53,786 & 4 \\
\hline 2 ACOLMAN & 44,727 & 50,537 & 57,103 & 1 \\
\hline 3 ACULCO & 29,869 & 32,589 & 35,557 & 4 \\
\hline 4 ALMOLOYA DE ALQUISIRAS & 12,244 & 13,108 & 14,032 & 5 \\
\hline 5 ALMOLOYA DE JUÁREZ & 85,836 & 92,395 & 99,454 & 3 \\
\hline 6 ALMOLOYA DEL RÍO & 6,906 & 7,405 & 7,940 & 3 \\
\hline 7 AMANALCO & 16,123 & 17,783 & 19,615 & \\
\hline 8 AMATEPEC & 28,273 & 28,603 & 28,936 & \\
\hline 9 AMECAMECA & 37,044 & 39,848 & 42,864 & 2 \\
\hline 10 APAXCO & $.18,856$ & 20,238 & 21,720 & 2 \\
\hline 11 ATENCO & 22,078 & 25,575 & 29,626 & 1 \\
\hline 12 ATIZAPÁN & 5,567 & 6,499 & 7,588 & 3 \\
\hline 13 ATIZAPÁN DE ZARAGOZA & 329,264 & 387,077 & 455,041 & 1 \\
\hline 14 ATLACOMULCO & 55,516 & 61,228 & 67,528 & 4 \\
\hline 15 ATLAUTLA & 19,477 & 21,378 & 23,464 & 2 \\
\hline 16 AXAPUSCO & 16,081 & 17,155 & 18,300 & 2 \\
\hline 17 AYAPANGO & 4,323 & 4,647 & 4,996 & 2 \\
\hline 18 CALIMAYA & 25,806 & 29,431 & 33,566 & 3 \\
\hline 19 CAPULHUAC & 21,869 & 24,287 & 26,972 & 3 \\
\hline 20 COACALCO & 158,698 & 185,807 & 217,547 & 1 \\
\hline 21 COATEPEC HARINAS & 28,281 & 29,581 & 30,941 & 5 \\
\hline 22 COCOTITLÁN & 8,233 & 8,873 & 9,563 & 2 \\
\hline 23 COYOTEPEC & 25,252 & 28,456 & 32,067 & 2 \\
\hline 24 CUAUTTITLÁN & 49,996 & 54,449 & 59,298 & 1 \\
\hline 25 CHALCO & 303,602 & 394,163 & 511,738 & 1 \\
\hline 26 CHAPA DE MOTA & 18,027 & 19,780 & 21,704 & 4 \\
\hline 27 CHAPULTEPEC & 4,027 & 4,698 & 5,480 & 3 \\
\hline 28 CHIAUTLA & 15,014 & 15,980 & 17,007 & 2 \\
\hline 29 CHICOLOAPAN & 59,136 & 66,435 & 74,637 & 1 \\
\hline 30 CHICONCUAC, & 14,354 & 15,023 & 15,722 & 2 \\
\hline 31 CHIMALHUACÁN & 261,478 & 346,613 & 459,468 & 1 \\
\hline 32 DONATO GUERRA & 21,952 & 23,668 & 25,519 & 5 \\
\hline 33 ECATEPEC & $1,249,827$ & $1,374,555$ & $1,511,731$ & 1 \\
\hline 34 ECATZINGO & 5,959 & 6,555 & 7,210 & 2 \\
\hline 35 HUEHUETOCA & 26,453 & 30,179 & 34,428 & 2 \\
\hline 36 HUEYPOXTLA & 26,845 & 29,423 & 32,247 & 2 \\
\hline 37 HUIXQUILUCAN & 136,604 & 155,421 & 176,830 & 1 \\
\hline 38 ISIDRO FABELAA & 5,373 & 6,107 & 6,942 & 3 \\
\hline 39 IXTAPALUCA & 143,645 & 169,547 & 200,119 & 1 \\
\hline 40 IXTAPAN DE LA SAL & 24,381 & 24,695 & 25,012 & 5 \\
\hline 41 IXTAPAN DEL ORO & 5,858 & 5,776 & 5,695 & 5 \\
\hline 42 IXTLAHUACA & 91,058 & 101,001 & 112,030 & 4 \\
\hline 43 JALATLACO & 14,509 & 16,355 & 18,435 & $3^{\prime}$ \\
\hline 44 JALTENCO & 23,266 & 25,066 & 27,005 & 1 \\
\hline 45 JILOTEPEC & 53,838 & 58,644 & 63,880 & 4 \\
\hline
\end{tabular}

continúa

\begin{tabular}{|c|c|c|c|c|}
\hline \multirow[t]{2}{*}{ MUNICIPIO } & \multicolumn{3}{|c|}{ POBLACIÓN ESTIMADA } & \multirow[t]{2}{*}{ REGIÓN } \\
\hline & 1991 & 1994 & 1997 & \\
\hline 46 JILOTZINGO & 9,434 & 11,183 & 13,256 & 3 \\
\hline 47 JIQUIPILCO & 45,008 & 48,897 & 53,123 & 4 \\
\hline 48 JOCOTITLÁN & 39,747 & 42,328 & 45,078 & 4 \\
\hline 49 JOQUICINGO & 8,081 & 9,349 & 10,816 & 3 \\
\hline 50 JUCHITEPEC & 14,692 & 16,367 & 18,233 & 2 \\
\hline 51 LERMA & 68,794 & 76,236 & 84,482 & 3 \\
\hline 52 MALINALCO & 17,308 & 19,023 & 20,907 & 5 \\
\hline 53 MELCHOR OCAMPO & 27,094 & 30,878 & 35,190 & 1 \\
\hline 54 METEPEC & 145,153 & 164,774 & 187,047 & 3 \\
\hline 55 MEXICALCINGO & 7,436 & 8,174 & 8,985 & 3 \\
\hline 56 MORELOS & 22,151 & 23,289 & 24,486 & 4 \\
\hline 57 NAUCALPAN & 793,962 & 822,025 & 851,080 & 1 \\
\hline 58 NEZAHUALCÓYOTL & $1,252,901$ & $1,241,069$ & $1,229,348$ & 1 \\
\hline 59 NEXTLALPAN & 11,362 & 13,527 & 16,103 & 1 \\
\hline 60 NICOLÁS ROMERO & 190,926 & 218,340 & 249,690 & 1 \\
\hline 61 NOPALTEPEC & 5,398 & 6,052 & 6,786 & 2 \\
\hline 62 OCOYOACAC & 38,236 & 41,519 & 45,084 & 3 \\
\hline 63 OCUILAN & 19,549 & 21,545 & 23,745 & 5 \\
\hline $64 \mathrm{EL} \mathrm{ORO}$ & 26,025 & 28,108 & 30,356 & 4 \\
\hline 65 OTUMBA & 22,315 & 24,189 & 26,220 & 2 \\
\hline 66 OTZOLOAPAN & 4,108 & 4,458 & 4,838 & 5 \\
\hline 67 OTZOLOTEPEC & 41,572 & 46,185 & 51,311 & 3 \\
\hline 68 OZUMBA & 18,501 & 20,262 & 22,191 & 2 \\
\hline 69 PAPALOTLA & 2,466 & 2,784 & 3,142 & 2 \\
\hline $70 \mathrm{LA} \mathrm{PAZ}$ & 140,326 & 162,919 & 189,150 & 1 \\
\hline 71 POLOTITLÁN & 9,826 & 10,254 & 10,700 & 4 \\
\hline 72 RAYÓN & 7,196 & 7,862 & 8,589 & 3 \\
\hline 73 SAN ANTONIO LA ISLA & 7,555 & 8,489 & 9,538 & 3 \\
\hline 74 SAN FELIPE DEL PROGRESO & 142,911 & 150,876 & 159,284 & 4 \\
\hline $\begin{array}{l}75 \text { SAN MARTÍN DE LAS } \\
\text { PIRÁMIDES }\end{array}$ & 13,995 & 15,720 & 17,657 & 2 \\
\hline 76 SAN MATEO ATENCO & 43,485 & 49,784 & 56,994 & 3 \\
\hline 77 SAN SIMÓN DE GUERRERO & 3,970 & 4,293 & 4,642 & 5 \\
\hline 78 SANTO TOMÁS & 7,227 & 7,849 & 8,525 & 5 \\
\hline 79 SOYANIQUILPAN & 8,049 & 8,247 & 8,449 & 4 \\
\hline 80 SULTEPEC & 23,643 & 24,328 & 25,032 & 5 \\
\hline 81 TECÁMAC & 126,551 & 139,701 & 154,217 & 1 \\
\hline 82 TEJUPILCO & 76,332 & 81,533 & 87,089 & 5 \\
\hline 83 TEMAMATLA & 5,653 & 6,858 & 8,319 & 2 \\
\hline 84 TEMASCALAPA & 19,786 & 22,554 & 25,710 & 2 \\
\hline 85 TEMASCALCINGO & 52,330 & 56,453 & 60,900 & 4 \\
\hline 86 TEMASCALTEPEC & 26,921 & 26,748 & 26,577 & 5 \\
\hline 87 TEMOAYA & 50,923 & 56,867 & 63,506 & 3 \\
\hline 88 TENANCINGO & 60,919 & 63,268 & 65,707 & 5 \\
\hline 89 TENANGO DEL. AIRE & 6,351 & 6,913 & 7,525 & 2 \\
\hline 90 TENANGO DEL VALLE & 47,126 & 51,739 & 56,804 & 3 \\
\hline
\end{tabular}




\begin{tabular}{|c|c|c|c|c|c|c|c|c|c|c|}
\hline so.tt & $\varepsilon<0^{\mathfrak{t}} \mathfrak{t}$ & $\mathfrak{I} \varepsilon \varsigma^{\prime} \mathfrak{I}$ & cos'6 & $8766^{\prime} \mathrm{s}$ & ธะO' $8 \mathrm{I}$ & $\forall 6 s^{\prime} \circ \varepsilon$ & NYd & NYd & NVd & 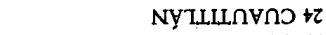 \\
\hline+688 & $s z z \mathfrak{t}$ & $6 t+1$ & $\varepsilon \varsigma 0^{\circ} \downarrow$ & $s+8^{2} z$ & $2+5.6$ & $\angle Z 9^{\circ} \mathrm{SI}$ & NVd & Crd & Ind & 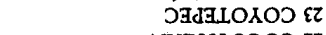 \\
\hline $0 \varsigma 8 z$ & $69<\mathfrak{t}$ & $z z 9$ & $99 \varepsilon$ & $t \varsigma \mathcal{E}^{\mathfrak{t}} \mathrm{\tau}$ & $90 r^{\prime} t$ & $\varepsilon t<L^{\prime} s$ & WaAd & IXd & Gdd & NYYLLLLOJOJ ZZ \\
\hline $10<4$ & $019^{\prime} z$ & $\angle \measuredangle$ & $8 \varepsilon \mathfrak{I}$ & $6 £ 0^{\prime} t$ & $+9 \tau^{\circ}<$ & 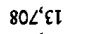 & Fid & ז्थd & กdd & SVNIYVH OAdG,LYOO IZ \\
\hline $8 \Gamma^{2} Z S$ & $609^{\circ} 9$ & $0+6 ' s$ & $9 z z ' \varepsilon z$ & $189 ‘ 81$ & $9 \mathrm{st} t \mathrm{tS}$ & \$88'EII & NYd & IXd & IXd & OОTVOVOJ OZ \\
\hline 99.87 & $\angle \$ L$ & $L \angle z^{\prime} z$ & ؟69' $\mathrm{I}$ & $\angle S 6^{6} \mathrm{I}$ & $0<9$ 9 & $686^{6} \mathrm{ZI}$ & add & IPd & IXdd & วษกHTกdVว 6I \\
\hline $\mathrm{L} \angle \mathbf{8 \varepsilon}$ & $6 \angle L^{\prime} \mathrm{t}$ & 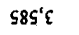 & +96 & $59 t^{\prime} \mathrm{E}$ & 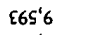 & ๕ฐ9'SI & add & Idd & IXd & VXVWITVD 8I \\
\hline L'£ & 28 & I8I & $68 L$ & $68 L$ & $I+8^{2} \mathrm{I}$ & $8+\angle Z Z$ & wo & Idd & ryd & OJNVdVXV $\angle I$ \\
\hline $8 \Gamma^{\circ} \mathcal{E} t$ & $\mathfrak{\varepsilon 6 <}$ & $58 \varepsilon$ & $\mathfrak{I}\left\langle\boldsymbol{S}^{\prime} \mathrm{I}\right.$ & $669^{\circ} \mathrm{r}$ & $8 t+t s$ & $885^{\prime} 6$ & I8d & red & red & 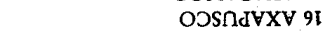 \\
\hline $8 I^{\circ} 6 t$ & $8 z s$ & $698^{\prime} \mathrm{z}$ & $z \varsigma s$ & $\angle 98^{\circ} \mathrm{t}$ & $918 \div \mathrm{s}$ & $s t+i t$ & ब\&d & md & ndd & VTLRVTILV SI \\
\hline$+6<t$ & \&รI' 1 & $288^{\prime} \mathrm{I}$ & $629^{\prime} \varepsilon$ & $+6 \varepsilon^{\prime} 8$ & $80 I^{\circ} \mathrm{SI}$ & $120^{\circ} 62$ & Ird & Pdd & Ird & OJTกWOJ VILL $\downarrow I$ \\
\hline $69^{\circ}\{\varsigma$ & $96 \varsigma^{`} \mathfrak{E I}$ & $06 \varepsilon^{2}+1$ & IZI'Et & $810^{\circ} 62$ & sZI'OOI & $9 z z^{\prime} 9 l z$ & NYd & Гلd & IXd & VZOSVUVZ ヨđ NYQdVZILV £ \\
\hline$\angle \varepsilon 6 t$ & $\cos$ & $\angle 0 z$ & 0 & 196 & $\varsigma \angle 9^{\prime} \mathrm{I}$ & $80 \mathcal{E}^{\prime} \mathcal{E}$ & Iवd & rod & Iथd & NYWdVZLLV \\
\hline $6 \tau^{2} \mathrm{It}$ & tot & $890^{\circ} \varepsilon$ & $90 L^{2} \mathrm{I}$ & $\tau+z^{t} \varepsilon$ & $9 T+8$ & $9 \llbracket \varepsilon^{\prime} b I$ & rad & NVd & red & OONGIV II \\
\hline$\varsigma \varsigma 8 \varepsilon$ & $90<$ & $68 t$ & $16 L^{\prime} \varepsilon$ & I56 $\mathrm{I}$ & $\angle E 6^{\prime} 9$ & $88 \mathrm{Z}^{\mathrm{t}} \mathrm{II}$ & NYd & rad & ryd & OJXVdV OI \\
\hline 6900 & $\angle z s^{\prime} z$ & $6+66^{\prime} z$ & $966^{t} \mathcal{E}$ & $9+\varepsilon^{5} t$ & $818^{\prime} \mathfrak{E I}$ & $66 z^{\prime} \mathcal{E Z}$ & Idd & red & Fod & 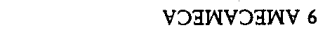 \\
\hline sZ'sא & $6 \mathrm{~K} / \mathrm{L}$ & $t \varsigma 9^{\prime} z$ & $6 \mathfrak{E I}$ & oor's & $219^{\circ} 8$ & $\mathcal{L O E} \mathfrak{E I}$ & Idd & red & İd & OAdGIVWV 8 \\
\hline $056 \mathrm{E}$. & $58 \tau^{\prime} z$ & $\forall 6 \varepsilon$ & $t$ & $z+\varepsilon^{\prime} z$ & $590^{\prime} \mathrm{s}$ & $\tau \measuredangle \varepsilon^{\prime} 8$ & Ird & rdd & Fid & OOTVNYWV L \\
\hline $80^{\circ} \mathrm{st}$ & ort & Lot & s\$9 & $\tau \angle I^{\prime} \mathrm{T}$ & $\mathfrak{\varepsilon} \varepsilon^{\mathfrak{c} Z}$ & $8+z^{\prime}+$ & IYd & กयd & IYd & Op̦ THA VXOTOWTV 9 \\
\hline $2+8 t$ & $20<\mathfrak{L}$ & OEI' & $+\angle 8^{x} \xi$ & $\varepsilon \angle 9^{\circ} 6$ & $6 \angle \mathcal{E}^{1} \mathfrak{\varepsilon} Z$ & $8 z \varepsilon^{\prime} S t$ & IXd & ryd & IYd & 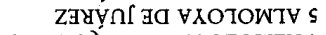 \\
\hline $\mathfrak{s} \mathfrak{s \mathcal { E }}$ & o๕z & 891 & $z \angle 8^{i} \mathrm{I}$ & $\varepsilon 60^{\circ} z$ & $\mathfrak{E q} \mathcal{E}^{\mathfrak{t}}$ & $6+\angle ' 9$ & rod & red & IYd & 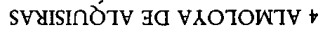 \\
\hline$\varepsilon 8 z \varepsilon$ & 818 & $89 \tau$ & $60 L^{t} \varepsilon$ & $60 I^{\prime} 9$ & $+06^{\prime} 01$ & $+\varepsilon z^{2} 9 \tau$ & เท่d & NYd & तथd & Oวากว $\varepsilon$ \\
\hline so $8 \varepsilon$ & t20't & $z z z^{\circ}$ or & $8 \varepsilon 8$ & $+66^{4} t$ & $8 \angle 0^{\circ} \angle I$ & $99 s^{\prime} \angle z$ & Codd & ryd & IXd & NVWTOOY $\tau$ \\
\hline sost & $9 S \tau^{\imath} \downarrow$ & $\angle 89$ & $8 \mathrm{IL} L^{t} \mathrm{~b}$ & $82+9$ & $680^{\circ} \mathrm{El}$ & $1 z 8^{\prime} \varepsilon \tau$ & Ird & Idd & ryd & $X \forall g W \forall \supset \forall I$ \\
\hline $89^{\circ} \varepsilon \varsigma$ & Is0'00t & $\varepsilon 20^{\circ}+6 \varsigma$ & $9 \angle S^{\prime} \angle \angle 8$ & $\angle 80^{\circ} z z 0^{\prime} \mathrm{I}$ & $\angle \varepsilon L^{\prime} \varepsilon \varsigma 8^{\prime} \tau$ & $98 I^{\prime} 19 I^{\prime} 9$ & & & & 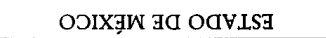 \\
\hline NOIONGISGY & SOY.LO & वृd & $\mathrm{NVd}$ & ryd & SOLOA & VISIT & \multirow{2}{*}{\multicolumn{3}{|c|}{ 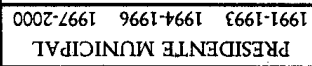 }} & \multirow[t]{2}{*}{ OIdIJINnW } \\
\hline$\%$ & \multicolumn{6}{|c|}{ 966I TVYOLOสาง OSสวOบd } & & & & \\
\hline
\end{tabular}

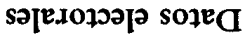

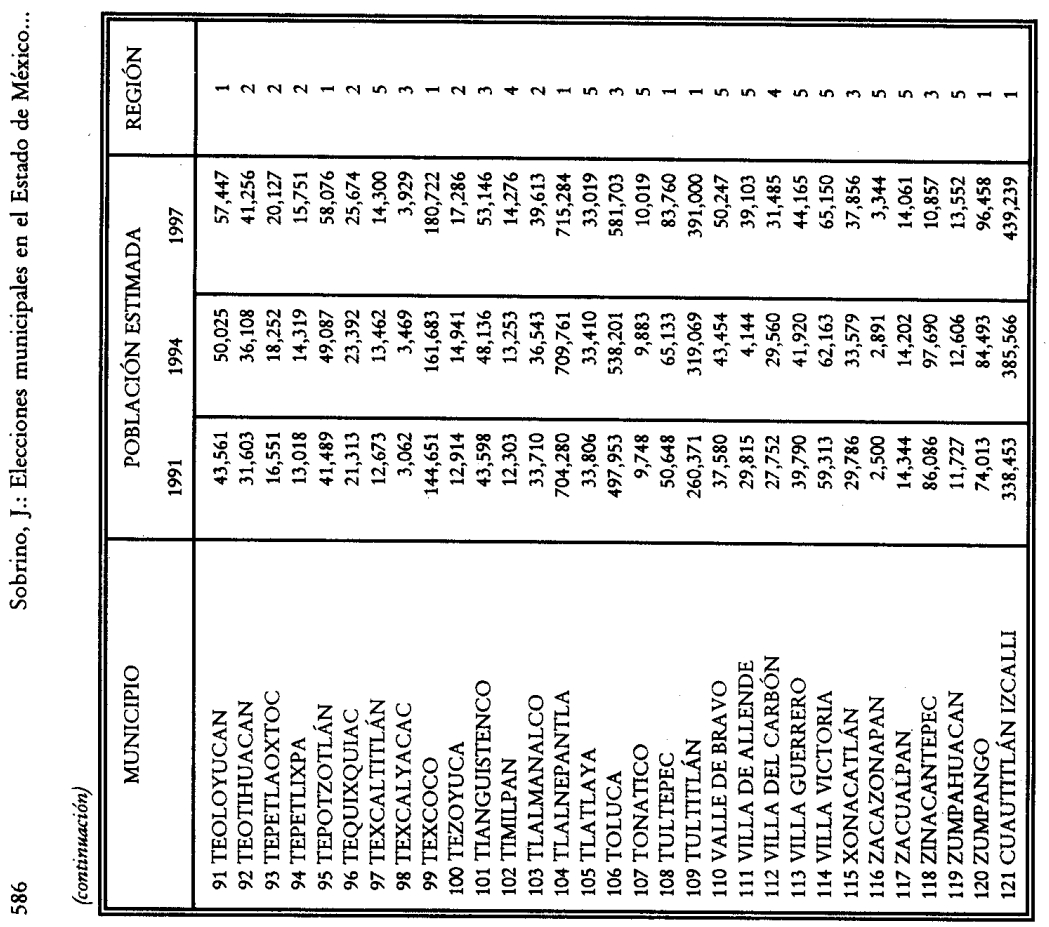




\begin{tabular}{|c|c|c|c|c|c|c|c|c|c|c|}
\hline \multirow[b]{2}{*}{ MUNICIPIO } & \multicolumn{3}{|c|}{ PRESIDENTE MUNICIPAL } & \multicolumn{6}{|c|}{ PROCESO ELECTORAL 1996} & \multirow{2}{*}{$\begin{array}{c}\% \\
\text { ABSTENCIÓN } \\
\end{array}$} \\
\hline & $1991-1993$ & 1994-1996 & $1997-2000$ & LISTA & VOTOS & $\mathrm{PRI}$ & PAN & PRD & OTROS & \\
\hline $25 \mathrm{CHALCO}$ & PRI & PRI & PRI & 79,731 & 34,714 & 12,207 & 9,319 & 7,391 & 5,797 & 56.46 \\
\hline 26 CHAPA DE MOTA & PRI & PRI & PRI & 9,183 & 5,381 & 2,586 & 1,980 & 391 & 424 & 41.40 \\
\hline 27 CHAPULTEPEC & PRI & PFCRN & PRI & 2,466 & 1,842 & 874 & 255 & 98 & 615 & 25.30 \\
\hline 28 CHIAUTLA & PRI & PRI & PRI & 9,500 & 5,542 & 2,428 & 1,299 & 1,551 & 264 & 41.66 \\
\hline 29 CHICOLOAPAN & PRI & PRI & PRI & 38,433 & 17,853 & 7,512 & 1,890 & 6,577 & 1,874 & 53.55 \\
\hline $30 \mathrm{CHICONCUAC}$ & PRD & PRI & PRD & 9,208 & 5,283 & 1,442 & 709 & 1,659 & 1,473 & 42.63 \\
\hline 31. CHIMALHUACÁN & PRI & PRI & PRI & 161,471 & 60,297 & 23,073 & 12,246 & 14,799 & 10,179 & 62.66 \\
\hline 32 DONATO GUERRA & PRI & PRI & PRI & 10,850 & 5,999 & 3,448 & 752 & 718 & 1,081 & 44.71 \\
\hline 33 ECATEPEC & PRI & PRI & PRI & 778,764 & 267,526 & 84,318 & 67,680 & 60,663 & 54,865 & 65.65 \\
\hline 34 ECATZINGO & PRI & PRI & PRI & 3,448 & 2,297 & 1,157 & 5 & 949 & 186 & 33.38 \\
\hline 35 HUEHUETOCA & PRI & PARM & PAN & 18,029 & 12,519 & 4,949 & 6,072 & 446 & 1,052 & 30.56 \\
\hline 36 HUEYPOXTLA & PRI & PRI & PRD & 15,769 & 9,037 & 3,446 & 458 & 4,675 & 458. & 42.69 \\
\hline 37 HUIXQUILUCAN & PRI & PRI & PRI & 87,225 & 41,518 & 15,522 & 12,508 & 8,194 & 5,294 & 52.40 \\
\hline 38 ISIDRO FABELA & PRI & PRI & PRD & 3,767 & 2,448 & 784 & 142 & 1,403 & 119 & 35.01 \\
\hline 39 IXTAPALUCA & PRI & PRI & PRI & 81,719 & 35,036 & 14,857 & 10,378 & 5,835 & 3,966 & 57.13 \\
\hline 40 IXTAPAN DE LA SAL & PRI & $\mathrm{PR}$ & PRI & 12,412 & 7,915 & 3,846 & 2,705 & 850 & 514 & 36.23 \\
\hline 41 IXTAPAN DEL ORO & PRI & PRI & PRI & 2,790 & 2,059 & 940 & 60 & 415 & 644 & 26.20 \\
\hline 42 IXTLAHUACA & PRI & PRI & PRI & 48,314 & 24,789 & 13,926 & 3,100 & 2,586 & 5,177 & 48.69 \\
\hline 43 JALATLACO & PRI & PRI & PRI & 7,427 & 2,283 & 1,455 & 63 & 497 & 268 & 69.26 \\
\hline 44 JALTENCO & PRI & PRI & PRI. & 13,824 & 6,307 & 3,351 & 1,686 & 750 & 520 & 54.38 , \\
\hline 45 JILOTEPEC & PRI & PRI & PRI & 29,826 & 18,453 & 9,903 & 5,866 & 1,180 & 1,504 & 38.13 \\
\hline 46 JILOTZINGO & PRI & PRI & PRI & 6,496 & 4,174 & 1,997 & 1,659 & 243 & 275 & 35.75 \\
\hline 47 JIQUIPILCO & PRI & PRI & PRD & 24,865 & 11,850 & 4,710 & 546 & 5,268 & 1,326 & 52.34 \\
\hline 48 JOCOTITLÁN & PRI & PRI & PRI & 22,848 & 12,631 & 8,065 & 1,870 & 1,601 & 1,095 & 44.72 \\
\hline 49 JOQUICINGO & PRI & PRI & PRD & 4,675 & 3,021 & 1,037 & 103 & 1,677 & 204 & 35.38 \\
\hline 50 JUCHITEPEC & PRI & PRD & PRI & 9,250 & 5,545 & 2,293 & 286 & 479 & 2,487 & 40.05 \\
\hline 51 LERMA & PRI & PRI & PAN & 42,044 & 25,277 & 9,555 & 11,925 & 2,223 & 1,574 & 39.88 \\
\hline 52 MALINALCO & PRI & PRI & PRI & 9,639 & 5,676 & 3,187 & 1,046 & 974 & 469 & 41.11 \\
\hline 53 MELCHOR OCAMPO & PRI & PRI & PAN & 17,188 & 10,732 & 3,647 & 4,563 & 2,080 & 442 & 37.56 \\
\hline
\end{tabular}

\begin{tabular}{|c|c|c|c|c|c|c|c|c|c|c|}
\hline \multirow[b]{2}{*}{ MUNICIPIO } & \multicolumn{3}{|c|}{ PRESIDENTE MUNICIPAL } & \multicolumn{6}{|c|}{ PROCESO ELECTORAL 1996} & \multirow{2}{*}{$\begin{array}{c}\% \\
\text { ABSTENCIÓN }\end{array}$} \\
\hline & 1991-1993 & $1994-1996$ & $1997-2000$ & LISTA & VOTOS & PRI & PAN & PRD & OTROS & \\
\hline 54 METEPEC & PRI & PRI & PRI & 92,343 & 53,098 & 19,816 & 14,523 & 6,657 & 12,102 & 42.50 \\
\hline 55 MEXICALCINGO & PRI & PRI & PRI & 4,341 & 2,393 & 1,181 & 153 & 975 & 84 & 44.87 \\
\hline 56 MORELOS & PRI & PRI & $\mathrm{PRI}$ & 11,336 & 5,835 & 3,008 & 1,470 & 556 & 801 & 48.53 \\
\hline 57 NAUCALPAN & PRI & PRI & PAN & 501,526 & 203,744 & 62,911 & 89,199 & 25,449 & 26,185 & 59.38 \\
\hline 58 NEZAHUALCÓYOTL & PRI & PRI & PRD & 796,437 & 312,724 & 86,730 & 70,530 & 102,096 & 53,368 & 60.73 \\
\hline 59 NEXTLALPAN & PRI & PRI & PRI & 7,221 & 4,574 & 2,094 & 2,058 & 216 & 206 & 36.66 \\
\hline 60 NICOLÁS ROMERO & PRI & PRI & PAN & 124,740 & 64,557 & 20,797 & 32,491 & 4,091 & 7,178 & 48.25 \\
\hline 61 NOPALTEPEC & PRI & PRI & PRI & 3,546 & 2,378 & 1,272 & 216 & 726 & 164 & 32.94 \\
\hline 62 OCOYOACAC & PRI & PRI & PRI & 22,960 & 13,079 & 5,493 & 4,361 & 2,181 & 1,044 & 43.04 \\
\hline 63 OCUILAN & PRI & PRI & PRI & 10,095 & 5,454 & 2,580 & 736 & 1,773 & 365 & 45.97 \\
\hline 64 EL ORO & PRI & PRI & PAN & 12,864 & 7,711 & 3,021 & 3,289 & 652 & 749 & 40.06 \\
\hline 65 OTUMBA & PRI & PRI & PRI & 12,748 & 7,158 & 2,608 & 2,118 & 1,706 & 726 & 43.85 \\
\hline 66 OTZOLOAPAN & PRI & PRI & PRD & 2,144 & 1,744 & 815 & 27 & 837 & 65 & 18.66 \\
\hline 67 OTZOLOTEPEC & PRI & PRI & PRD & 22,959 & 13,150 & 4,860 & 196 & 7,084 & 1,010 & 42.72 \\
\hline 68 OZUMBA & PRI & PRI & PRD & 11,551 & 6,388 & 2,326 & 250 & 2,642 & 1,170 & 44.70 \\
\hline 69 PAPALOTLA & PRI & PRI & PAN & 1,985 & 1,474 & 553 & 818 & 78 & 25 & 25.74 \\
\hline 70 LA PAZ & PRI & PRI & PRD & 81,185 & 34,769 & 11,443 & 4,100 & 14,040 & 5,186 & 57.17 \\
\hline 7.1 POLOTITLÁN & PRI & PRI & PRI & 6,638 & 4,608 & 2,255 & 573 & 1,385 & 395 & 30.58 \\
\hline 72 RAYÓN & PRI & PRI & PRI & 4,314 & 2,781 & 1,249 & 1,083 & 304 & 145 & 35.54 \\
\hline 73 SAN ANTONIO LA ISLA & PRI & PAN & PRI & 4,762 & 3,581 & 1,857 & 1,128 & 22 & 574 & 24.80 \\
\hline 74 SAN FELIPE DEL PROGRESO & PRI & PRI & PRI & 63,658 & 29,710 & 14,555 & 10,195 & 974 & 3,986 & 53.33 \\
\hline \multicolumn{10}{|l|}{75 SAN MARTÍN DE LAS } & 33.34 \\
\hline 76 SAN MATEO ATENCO & PRI & PRI & PRD & 26,440 & 16,620 & 5,777 & 2,446 & 6,983 & 1,414 & 37.14 \\
\hline 77 SAN SIMÓN DE GUERRERO & PRI & PRI & PRI & 2,307 & 1,499 & 1,006 & 77 & 321 & 95 & 35.02 \\
\hline 78 SANTO TOMÁS & PRI & PRI & PRI & 3,980 & 2,736 & 1,023 & 760 & 722 & 231 & 31.26 \\
\hline 79 SOYANIQUILPAN & PRI & PRI & PRI & 4,662 & 3,347 & 1,847 & 1,196 & 142 & 162 & 28.21 \\
\hline
\end{tabular}




\begin{tabular}{|c|c|c|c|c|c|c|c|c|c|c|}
\hline \multirow[b]{2}{*}{ MUNICIPIO } & \multicolumn{3}{|c|}{ PRESIDENTE MUNICIPAL } & \multicolumn{6}{|c|}{ PROCESO ELECTORAL 1996} & \multirow{2}{*}{$\begin{array}{c}\% \\
\text { ABSTENCIÓN } \\
\end{array}$} \\
\hline & 1991-1993 & 1994-1996 & $1997-2000$ & LISTA & VOTOS & PRI & PAN & PRD & OTROS & \\
\hline 80 SULTEPEC & $\mathrm{PRI}$ & PRI & PRI & 10,978 & 6,380 & 3,700 & 1,675 & 265 & 740 & 41.88 \\
\hline 81. TECÁMAC & PRI & PRI & PAN & 75,588 & 39,218 & 13,934 & 19,502 & 3,063 & 2,719 & 48.12 \\
\hline 82 TEJUPILCO & PRI & PRI & PRI & 38,761 & 19,262 & 9,278 & 1,077 & 7,463 & 1,444 & 50.31 \\
\hline 83 TEMAMATLA & PRI & PRI & PRI & 4,404 & 2,197 & 971 & 712 & 75 & 439 & 50.11 \\
\hline 84 TEMASCALAPA & PRI & PRJ & PAN & 12,035 & 7,833 & 2,945 & 3,802 & 710 & 376 & 34.91 \\
\hline 85 TEMASCALCINGO & PRI & PRI & PRI & 26,960 & 13,911 & 6,256 & 875 & 5,456 & 1,324 & 48.40 \\
\hline 86 TEMASCALTEPEC & $\mathrm{PRI}$ & PRI & PRI & 12,694 & 6,991 & 3,964 & 1,434 & 984 & 609 & 44.93 \\
\hline 87 TEMOAYA & PRI & PRI & PRI & 25,876 & 11,616 & 6,187 & 1,920 & 1,820 & 1,689 & 55.11 \\
\hline 88 TENANCINGO & PRI & PRI & PAN & 34,104 & 20,110 & 5,985 & 11,711 & 896 & 1,518 & 41.03 \\
\hline 89 TENANGO DEL AIRE & $\mathrm{PRI}$ & PRI & PRD & 4,477 & 3,362 & 1,285 & 274 & 1,642 & 161 & 24.91 \\
\hline 90 TENANGO DEL VALLE & PRI & PRI & PAN & 25,133 & 14,498 & 6,281 & 6,490 & 785 & 942 & 42.31 \\
\hline 91 TEOLOYUCAN & PRI & PRI & PRD & 26,221 & 15,644 & 4,500 & 3,775 & 5,498 & 1,871 & 40.34 \\
\hline 92 TEOTIHUACAN & PRI & PRI & PRD & 21,216 & 12,772 & 4,414 & 917 & 6,729 & 712 & 39.80 \\
\hline 93 TEPETLAOXTOC & PRI & PRD & PRD & 9,914 & 6,420 & 2,935 & 87 & 2,937 & 461 & 35.24 \\
\hline 94 TEPETLIXPA - & PRI & PRI & PRI & 7,956 & 4,721 & 2,042 & 66 & 823 & 1,790 & 40.66 \\
\hline 95 TEPOTZOTLÁN & PRI & PAN & PAN & 28,542 & 18,404 & 5,423 & 8,914 & 2,425 & 1,642 & 35.52 \\
\hline 96 TEQUIXQUIAC & PRD & PRI & PRI & 12,447 & 6,538 & 3,992 & 1,178 & 1,090 & 278 & 47.47 \\
\hline 97 TEXCALTTTLÁN & PRI & PRI & PRI & 6,369 & 4,372 & 2,287 & 31 & 1,733 & 321 & 31.36 \\
\hline 98 TEXCALYACAC & PRI & PRI & PRD & 1,969 & 1,306 & 615 & 0 & 642 & 49 & 33.67 \\
\hline 99 TEXCOCO & PRI & PRI & PRD & 89,516 & 48,199 & 15,678 & 3,760 & 24,479 & 4,282 & 46.16 \\
\hline 100 TEZOYUCA & PRI & PRI & PRI & 8,891 & 5,322 & 2,755 & 1,717 & 573 & 277 & - 40.14 \\
\hline 101 TIANGUISTENCO & PRI & PRI & PRI & 23,725 & 13,391 & 5,585 & 3,629 & 3,013 & 1,164 & 43.56 \\
\hline 102 TIMILPAN & PRI & PRI & PRI & 6,861 & 4,653 & 2,166 & 1,923 & 203 & 361 & 32.18 \\
\hline 103 TLALMANALCO & PRI & PRI & PRD & 22,570 & 12,088 & 4,044 & 1,027 & 5,534 & 1,483 & 46.44 \\
\hline 104 TLALNEPANTLA & PRI & PRI & PAN & 443,299 & 179,219 & 58,921 & 65,474 & 29,722 & 25,102 & 59.57 \\
\hline 105 TLATLAYA & PRI & PRI & PRI & 15,889 & 9,717 & 6,097 & 190 & 2,922 & 508 & 38.84 \\
\hline 106 TOLUCA & PRJ & PRI & PRI & 308,784 & 162,045 & 61,974 & 58,742 & 17,797 & 23,532 & 47.52 \\
\hline 107 TONATICO & PRI & PRI & PRD & 5,926 & 4,242 & 1,974 & 69 & 2,053 & 146 & 28.42 \\
\hline
\end{tabular}

\begin{tabular}{|c|c|c|c|c|c|c|c|c|c|c|}
\hline \multirow[b]{2}{*}{ MUNICIPIO } & \multicolumn{3}{|c|}{ PRESIDENTE MUNICIPAL } & \multicolumn{6}{|c|}{ PROCESO ELECTORAL 1996} & \multirow{2}{*}{$\begin{array}{c}\% \\
\text { ABSTENCIÓN }\end{array}$} \\
\hline & 1991-1993 & 1994-1996 & $1997-2000$ & LISTA & VOTOS & PRI & PAN & PRD & OTROS & \\
\hline 108 TULTEPEC & PRI & PRI & PRD & 32,432 & 16,441 & 4,545 & 4,842 & 5,628 & 1,426 & 49.31 \\
\hline 109 TULTITLÁN & PRI & PRI & PRI & 174,603 & 76,626 & 24,451 & 19,682 & 22,168 & 10,325 & 56.11 \\
\hline 110 VALLE DE BRAVO & PRI & PRI & PAN & 24,153 & 15,713 & 4,778 & 8,910 & 827 & 1,198 & 34.94 \\
\hline 111 VILLA DE ALLENDE & PRI & $\mathrm{PRJ}$ & PRI & 15,441 & 7,312 & 4,378 & 1,102 & 702 & 1,130 & 52.65 \\
\hline 112 VILLA DEL CARBÓN & PRI & PRI & PAN & 14,958 & 10,072 & 4,164 & 4,880 & 115 & 913 & 32.66 \\
\hline 113 VILLA GUERRERO & PRI & PFCRN & PRI & 20,328 & 12,870 & 4,776 & 620 & 451 & 7,023 & 36.69 \\
\hline 114 VILLA VICTORIA & PRI & PRI & PRI & 27,461 & 13,774 & 7,345 & 1,247 & 2,307 & 2,875 & 49.84 \\
\hline 115 XONACATLÁN & PRI & PRI & PRD & 18,135 & 12,201 & 5,209 & 422 & 5,246 & 1,324 & 32.72 \\
\hline 116 ZACAZONAPAN & PRI & PRI & PRI & 1,357 & 906 & 589 & 21 & 216 & 80 & 33.24 \\
\hline 117 ZACUALPAN & PRI & PRI & PRI & 6,901 & 3,577 & 1,710 & 1,081 & 456 & 330 & 48.17 \\
\hline 118 ZINACANTEPEC & PRI & PRI & PRI & 48,514 & 26,419 & 12,440 & 7,480 & 3,185 & 3,314 & 45.54 \\
\hline 119 ZUMPAHUACAN & PRI & PRI & PRI & 6,190 & 4,044 & 2,158 & 213 & 1,361 & 312 & $34.67^{\prime}$ \\
\hline 120 ZUMPANGO & PRI & PRI & PRD & 46,054 & 23,666 & 9,183 & 3,054 & 9,724 & 1,705 & 48.61 \\
\hline 121 CUAUTITLÁN IZCALLI & PRI & PRI & PAN & 216,804 & 111,020 & 32,672 & 48,427 & 16,080 & 13,841 & 48.79 \\
\hline 122 VALLE DE CHALCO & & & & & & & & & & \\
\hline SOLIDARIDAD & & & PRI & 114,582 & 51,751 & 18,787 & 11,392 & 11,357 & 10,215 & 54.83 \\
\hline
\end{tabular}

Fuente: Instituto Electoral del Estado de México. 


\section{Bibliografía}

Arenas, Ernesto, Fernando Bahena y Antonio Sánchez (1995) "Geografía electoral en el Estado de México", Cuestión regional, Toluca, Universidad Autónoma del Estado de México-Universidad del Cauca.

Arreola Ayala, Álvaro (1995), La sucesión en la gubernatura del Estado de México 1917-1993, Zinacantepec, El Colegio Mexiquense.

y Juan Molinar Horcasitas (1988), "Procesos electorales en México", Revista Mexicana de Sociología, año L, núm. 2, pp. 241-267.

Byrne, Tony (1986), Local Government in Britain, Hardmondsworth, Penguin Books.

Cabrero, Enrique, Rodolfo García del Castillo y Martha Gutiérrez (1995), La nueva gestión municipal en México. Análisis de experiencias innovadoras en gobiernos locales, México, Miguel Ángel Porrúa-Centro de Investigación y Docencia Económicas.

Conde, Carola (1996), “Aspectos relevantes de la innovación municipal", Simposio Internacional sobre Desarrollo Municipal: Retos y Posibilidades, Zinacantepec, El Colegio Mexiquense.

Cotteret, Jean Marie y Claude Emeri (1973), Los sistemas electorales, Barcelona, Ediciones Oikos-Tau.

Crespo, José Antonio (1996), Votar en los estados. Análisis comparado de las legislaciones electorales estatales en México, México, Fundación Friedrich Naumann-Centro de Investigación y Docencia Económicas.

Downs, Alvin (1957), An Economic Theory of Democracy, Nueva York, Harper and Row Publishers.

Emmerich, Gustavo (coord.) (1993), Votos y mapas, Toluca, Universidad Autónoma del Estado de México.
Garza, Gustavo (1996), Cincuenta años de investigación urbana $y$ regional en México, 1940-1991, México, El Colegio de México.

Gobierno del Estado de México (1993a), Plan de Desarrollo del Estado de México 1993-1999, Toluca, Gobierno estatal.

- (1993b), Ley de Organizaciones Políticas y Procedimientos Electorales del Estado de México, Toluca, Tribunal Estatal de lo Contencioso Electoral.

- (1996a), Prontuario de Legislación Fiscal 1996, Toluca, Secretaría de Finanzas y Planeación.

(1996b), Código Electoral del Estado de México, Toluca, Gobierno estatal.

Graizbord, Boris y Jaime Sobrino (1990), "Geografía política de la región metropolitana de la ciudad de México", en Actas Latinoamericanas de Varsovia, tomo 11, Varsovia.

Hirsh, Werner (1977), Análisis de economía urbana, Madrid, Instituto de Estudios de Administración Local.

Instituto Nacional de Estadística, Geografía e Informática (INEGI) (1996a), Estados Unidos Mexicanos. Conteo de población y vivienda 1995. Resultados definitivos, Aguascalientes, INEGI.

_- (1996b), Sistema de cuentas nacionales de México. Producto interno bruto por entidad federativa 1993, Aguascalientes, INEGI.

Johnston, Ronald, Fred Shelley y Peter Taylor (1990), Developments in Electoral Geography, Londres, Routledge.

López Chavarría, José Luis (1988), Las elecciones municipales y la renovación política electoral, México, Secretaría de Gobernación/Centro Nacional de Estudios Municipales.

Martínez Cabañas, Gustavo (1993), La administración estatal y municipal en México, México, Instituto Nacional de Administración Pública. 
Massé, Carlos (1993), Una proposición metodológica para el estudio y eldesarrollomunicipal,Zinacantepec, El Colegio Mexiquense.

Muth, Richard (1975), Urban Economic Problems, Nueva York, Harper and Row Publishers.

Pacheco, Guadalupe (1991), “¿Por qué vota un elector?”, en Jorge Hernández Campos et al., Partidospolíticosy ciudadanos:entre el diálogo y la mercadotecnia, México, Cambio XXI, Fundación Mexicana A.C.

Panebianco, Angelo (1982), Modelos de partido, Madrid, Alianza Editorial.

Richards, Peter (1983), The Local Government System, Londres, George Allen and Unwin.

Rose, Richard (1980), Electoral Participation, Londres, Sage Publications.

Salazar, Julián y Gustavo Emmerich (1993), "Ensayo de geografía electoral del Estado de México", en Gustavo Emmerich (ed.), Votos y mapas, Toluca, Universidad Autónoma del Estado de México.

Sanguín, André-Louis (1981), Geografía política, Barcelona, OikosTau.

Secretaría de Gobernación (SEGOB) (1992), Información básica de los municipiosde México, México, Centro Nacional de Desarrollo Municipal.

- (1994), La autoridad municipal y su compromiso con la democracia, México, Centro Nacional de Desarrollo Municipal.

Sobrino, Jaime y Carlos Garrocho (1995), Pobreza, politica social y participación ciudadana, Zinacantepec, El Colegio Mexiquense-Secretaría de Desarrollo Social.
Ziccardi, Alicia (1994), "Gobiernos locales: problemas de la representación y la participación ciudadana”, en SEGOB, $L a$ autoridad municipal y su compromiso con la democracia, México, Centro Nacional de Desarrollo Municipal. 